\title{
Spatial differences in growth of lesser sandeel in the North Sea
}

\author{
Rindorf, Anna; Wright, Peter J.; Jensen, Henrik; Maar, Marie
}

Published in:

Journal of Experimental Marine Biology and Ecology

Link to article, DOI:

10.1016/j.jembe.2016.02.007

Publication date:

2016

Document Version

Peer reviewed version

Link back to DTU Orbit

Citation (APA):

Rindorf, A., Wright, P. J., Jensen, H., \& Maar, M. (2016). Spatial differences in growth of lesser sandeel in the North Sea. Journal of Experimental Marine Biology and Ecology, 479, 9-19.

https://doi.org/10.1016/j.jembe.2016.02.007

\section{General rights}

Copyright and moral rights for the publications made accessible in the public portal are retained by the authors and/or other copyright owners and it is a condition of accessing publications that users recognise and abide by the legal requirements associated with these rights.

- Users may download and print one copy of any publication from the public portal for the purpose of private study or research.

- You may not further distribute the material or use it for any profit-making activity or commercial gain

- You may freely distribute the URL identifying the publication in the public portal

If you believe that this document breaches copyright please contact us providing details, and we will remove access to the work immediately and investigate your claim. 


\section{Spatial differences in growth of lesser sandeel in the North Sea}

2 Anna Rindorf ${ }^{a^{*}}$, Peter J. Wright ${ }^{\mathrm{b}}$, Henrik Jensen $^{\mathrm{a}}$ and Marie Maar ${ }^{\mathrm{c}}$

3 Technical University of Denmark, National Institute of Aquatic Resources, Charlottenlund

4 Slot, DK2920 Charlottenlund, Denmark.

5 bMarine Scotland Science, Marine Laboratory, 375 Victoria Road, Aberdeen, AB11 9DB,

6 Scotland, UK

7 'Department of Bioscience, Aarhus University, Frederiksborgvej 399, PO Box 358, 4000

8 Roskilde, Denmark

$9 \quad{ }^{*}$ Corresponding author. Email: ar@aqua.dtu.dk

11 Abstract

12 Lesser sandeel, Ammodytes marinus, is a key prey to a variety of North Sea

13 predators, including species such as single load seabirds which are highly sensitive to prey

14 size and condition. While differences in weight at age across the North Sea have been

15 investigated previously, the scale and cause of this variation as well as the potential link

16 to spatial differences in predator performance remains unknown. This study presents an

17 analysis of spatial patterns in length and condition of the lesser sandeel in the North Sea

18 and the relationship of these with physical and biological factors. Both mean length at age

19 and condition was found to be higher on warmer, deeper and central/north eastern

20 fishing grounds. Sandeel in the water column exhibited large changes in condition over

21 the season, having an initially low condition following spring emergence rising to a 
22 pronounced peak by June. Weight at age varied considerable both spatially and

23 temporally, resulting in 4 fold and 1.9 fold variation in the number of sandeels required to

24 obtain a specific weight, respectively. Hence, the value of sandeel as prey to single load

25 predators varies considerably with values in central and northeastern North Sea being

26 substantially higher than in northwestern and southern areas.

27

28 Highlights

37 Key words: Lesser sandeel, length, condition, temperature, spatial differences

- Spatial differences in growth resulted in 4-fold differences in weight at age 2

- Sandeel condition increased 1.5-fold over the season from early spring to June

- Spatio-temporal distribution of the fishery produced peaks in observed weight

- To obtain a kg of sandeel, the number of prey a predator must ingest varies 6-fold

36 


\section{Introduction}

The lesser sandeel, Ammodytes marinus (L.), is a small elongate planktivorous fish

which forms an important prey source for numerous fish, seabirds and mammals (Daan et al., 1990; Furness, 1990; Engelhard et al., 2014). Beyond their first year of life, their growth season spans only a few months in spring and early summer (Winslade, 1974a;

Pedersen et al., 1999; Bergstad et al., 2002) and their spatial distribution is highly restricted (Wright et al., 2000; Jensen et al., 2011), making their importance particularly impressive. Outside these months, sandeel older than 1 year remain buried in the sediment, emerging only in mid-winter to spawn.

In their role as prey for numerous predators, weight and length at age is of great importance as the benefit of sandeel prey to predators depends on the ratio between handling time and prey energy content (Stephens and Krebs, 1986), a ratio to which single prey loading seabirds are particularly sensitive (Wanless et al., 2005). Predators targeting sandeel are likely to experience only minor changes in handling time but profound changes in the weight of prey items with differing prey size. Weight and length at age has been reported to differ across the North Sea, although the evidence for this is partially confounded by differences in the years and areas sampled and the studies cover only a small part of the total distribution area (Macer, 1966; Wright, 1996; Bergstad et al., 2002; Boulcott et al., 2007). If present, spatial differences may potentially explain why strong links between sandeel density and dependent predators such as seabirds have been reported for the north western North Sea (Monaghan, 1992; Rindorf et al., 2000) while further south the eastern English kittiwake populations apparently maintain high 
60

61

62

63

64

65

66

67

68

69

70

71

72

73

74

breeding success even in years of sandeel recruitment failure and low adult sandeel biomass (Frederiksen et al., 2005; ICES, 2014).

The factors that may affect length and condition include prey and competitor abundance as well as temperature. Temperature directly determines several vital physiological processes in fishes (Jobling, 1985), including food consumption and assimilation rate (Brett, 1979). Positive direct thermal effects on the rate of increase in length and condition will occur when food availability is not limiting and temperature is within the aerobic scope for growth (Pörtner and Rainer, 2007). Over the North Sea, surface and bottom temperatures generally vary by around 3 to $5^{\circ} \mathrm{C}$ during summer (Elliot et al., 1991) and hence spatial differences in temperature could potentially introduce variability in scope for growth. Sandeel are visual feeders on zooplankton, particularly calanoid copepods (Macer, 1966; Winslade, 1974a; van Deurs et al., 2014) and if food is limiting, growth rate will reflect the temporally and spatially varying abundance of prey. Several authors have suggested that growth rate decreases late in the season when food is less abundant (Pedersen et al., 1999; Bergstad et al., 2002) and high local densities may inhibit growth rate through food competition (Bergstad et al., 2002).

Sandeels accumulate large amounts of lipids in their somatic tissue over the foraging season for somatic maintenance and secondary gonad development during the overwinter phase (Hislop et al., 1991; Boulcott and Wright, 2008). The onset of overwintering depends on the build-up of lipid reserves with long or high condition sandeel burying earlier than small individuals (Bergstad et al., 2002; Wanless et al., 2004, van Deurs et al., 2011). Therefore, both regional differences in growth rate and sizedifferentiated timing of emergence periods may lead to temporal changes in weight at 
83

84

85

86

87

88

89

90

91

\section{$97 \quad 2$ Material and methods}

Length and condition were analysed separately in this study. These two parameters differ in that length is generally monotonically increasing whereas condition may decrease and rather than weight at age has the further advantage that they are statistically

age. Such changes appear in commercial catches where weight at age seems to peak midseason (Pedersen et al., 1999). However, as there are likely to be regional differences in length and condition, the observed pattern in weight at age may be a sampling artefact caused by temporal changes in the areas fished by the commercial fishery.

This study presents an investigation of length and condition at age of sandeel with the aim to determine (1) whether there are spatial differences in length and condition at age, (2) whether such spatial differences can be explained by differences in biophysical conditions, (3) whether a decrease in weight at age late in the season as reported by Pedersen et al. (1999) is an artefact caused by spatially dependent length and a geographical change in fishing effort, (4) whether site specific decreases in length and condition at age occur late in the season indicating early burial of long or high condition fish and finally, (5) what are the consequences of spatiotemporal differences in weight at age on the number of sandeel required to obtain a kg by area. increase again over the course of the year. Hence, a decrease in length at age is likely to be caused by removal of large individuals from the population whereas this cannot be assumed for a decrease in condition or weight at age. Analysing length and condition independent and can therefore be compared without the risk of spurious correlations 
105 arising. Variation in length and condition was analysed spatially, ignoring cohort and

106 other temporal effects, as the data available were too unbalanced to allow a joint analysis

107 of spatial and temporal variation.

$108 \quad 2.1 \quad$ Sandeel fishing ground definition

109 Fishing ground distribution was used to determine the distribution of foraging habitat

110 (Jensen et al. 2011). Sandeels show extensive movements within fishing grounds but very

111 limited movements between grounds (Kunzlik et al., 1986; Jensen et al. 2011). Therefore,

112 all data on physical and biological conditions were averaged within fishing ground before

113 further analyses. The only exception to this was the largest fishing ground, where

114 analyses indicate that some spatial structure exists in length composition (Jensen et al.

115 2011).

$116 \quad 2.2 \quad$ Sandeel biological data

117 Sandeel data for the analyses were derived from a co-operation between the Danish

118 Fishermens Association and the Technical University of Denmark that started in 1999.

119 Samples of sandeel data up to 2010 were included in analyses, providing a full time span

120 of 12 years. After 2010, the number of samples is lower and the spatio-temporal coverage

121 changed in some years due to severe limitations on the fishery. The fishery targets several

122 species of sandeel of which $A$. marinus is by far the most important and the focus of this

123 study. Samples were collected by fishers directly from fishing vessels and the exact

124 location and time of shooting and hauling of the trawl and the estimated total weight of

125 the catch in the haul were recorded for each sample. Approximately $1 \mathrm{~kg}$ samples of

126 sandeel were taken randomly from the catch. Bycatch of other species in the sandeel

127 fishery consists of a very low percentage of gadoids and these were not included in the 
128 samples. In the laboratory, sandeel were sorted by species, and total length, L, in a

129 subsample of $A$. marinus measured to the nearest half $\mathrm{cm}$ below. Comparison of the

130 length distribution of these samples with randomly selected port samples taken from

131 vessel landings indicated that there was no bias induced by fishermen's sampling. 5 to 10

132 sandeel per half $\mathrm{cm}$ group were randomly selected and age estimated using the sagitta

133 otoliths. Age estimation was conducted by two readers following ICES protocols on the

134 seasonal appearance of translucent and opaque zones in sandeel otoliths and the

135 identification of secondary growth structures using daily increments (Wright, 1993; ICES,

136 1995). Reader agreement tested in workshops with other institutions was $83 \%$ for all ages

137 (e.g. ICES, 2006). As age estimation agreement tends to decrease with age (ICES, 1995),

138 fish of age 4 and older were grouped into a plus-group. Fishing ground was assigned to

139 samples from the location of the midpoint of the haul.

140 Mean length at age was estimated by combining sampled length distributions with

141 age-length keys. Age-length keys were produced separately for each fishing ground in

142 each week and year using the method described by Rindorf and Lewy (2001) on all data

143 available from the given fishing ground, week and year. Where possible, only data from

144 the particular week in which a length sample was taken were used to estimate the age

145 length key for the sample. If less than 50 sandeel were aged in a specific week or weekly

146 data resulted in confidence intervals of the predicted proportion at age which were larger

147 than 0.25, 2-week periods were used to estimate the age-length key. No further temporal

148 aggregation of samples was conducted to ensure that no bias was introduced in length at

149 age by using incorrect age-length keys. Each haul resulted in one mean length at age for

150 each age group except if the predicted number at age was below 5 . Mean lengths based

151 on less than 5 fish were judged to be highly uncertain and excluded. Hence, number of 
152 mean lengths available differed between ages as not all ages were sufficiently

153 represented in all samples. Age 0 sandeels were only partly selected by the fishing gear

154 and hence were not included in analyses of length and condition. Due to uncertainty in

155 the true age of 4+ sandeel, this age group was not included in the von Bertalanffy

156 analyses. There was no subsequent weighting of the samples to reflect the catch in the

157 haul from which the sample was taken or the number length measured in the sample.

158 Average condition $C$ of fish of length $L$ in each sample was estimated from the

159 average weight $W$ of fish of this length in the sample (Le Cren, 1951):

$160 C=W / L^{b}$

161 The parameter $b$ was the exponent estimated from the length-weight relationship

162 derived from all samples together:

$163 W=C_{m} L^{b}$

164

where $C_{m}$ denotes the monthly average condition across all years and fishing grounds.

165

The error around the relationship was assumed to be gamma distributed as the variation

166

in weight increased with the mean. The average condition of each age group recorded in

167

a sample was estimated as the average between half $\mathrm{cm}$ groups, weighted by the number

168 of fish of the given age in the half $\mathrm{cm}$ group.

Catch in numbers per minute was assumed to be an index of density (Hilborn and Walters, 1992) and was estimated by combining catch in $\mathrm{kg} /$ minute haul time with the

171 number of sandeel per kg in the particular haul. The geometric average catch in numbers

172 per minute (all ages together) on each fishing ground in the particular week averaged

173 over all years was used as an index of sandeel density. 
174

175

176

177

178

179

180

181

182

\subsection{Biophysical conditions}

Average predicted biophysical conditions were derived from models as samples with sufficient spatio-temporal coverage were not available. The model predictions are average values based on information from a large number of individual samples whereas the sandeel mean length and condition are observations based on single samples. The sampling error in sandeel length and condition is therefore likely to be substantially larger than that of model predicted biophysical conditions, allowing the use of biophysical variables as independent factors in models without the use of methods, such as functional regression, to correct for variability in the independent factors.

Average predicted bottom and surface temperatures at each fishing ground across all years was taken from a 3 dimensional finite difference hydrodynamic model set up in spherical coordinates (She et al., 2007). Temperature within each fishing ground was estimated as the average temperature of locations within the fishing ground, averaged over the months March to June, since this is considered to be the period of most active feeding and growth (Macer, 1966; Bergstad et al., 2002; van der Kooij et al., 2008), and the years from 1999 to 2008.

Data on protozooplankton and copepods were generated by a 3D circulation model (She et al., 2007) coupled to the Ecological ReGional Ocean Model (ERGOM) for the years 2004-2006 (Maar et al., 2011). The version used contains 11 pelagic state variables describing nitrogen cycling through 3 groups of phytoplankton (diatoms, flagellates and blue-green algae), microzooplankton, mesozooplankton, and detritus and sea water concentrations of nutrients $\left(\mathrm{NO}_{3}, \mathrm{NH}_{4}, \mathrm{PO}_{4}, \mathrm{SiO}_{2}\right)$ and dissolved $\mathrm{O}_{2}$. Model data of both zooplankton groups is summed, vertically integrated and the ground specific average over 
197 the months March to June estimated over all three years. The accuracy of model

198 predictions for mesozooplankton biomass has been verified by comparison with field 199 samples by Gürkan et al. (2013) and Maar et al. (2014). Plankton data were only available 200 for the years 2004 to 2006 and temperature data from 1999 to 2008. Maps of the 201 biophysical input variables can be seen in fig. 1.

\section{Calculation}

204

205

206

207

208

209

210

211

212

213

214

\subsection{Estimating growth age}

As sandeels feed and grow in a limited period during spring and summer, the growth function used to describe length at age should take account of this rather than assume constant length growth over the year. A solution to this is to estimate the 'growth age', $t_{g}$, as the difference between true age (in decimal years) $t_{a}$ and the time spent buried, the product of the length of the buried season $t_{b}$, and the age in years, $t_{y}$, equal to $0,1,2$ or $3:$

$t_{g}=t_{a}-t_{y} t_{b}$

By subtracting buried periods, length becomes a smooth function of time for fish caught during the growth period. The duration of the length growth period was estimated to be 15.0 weeks (Supplementary material). Age 0 was set to week 12 of the year of hatching as this was the first week where samples were available. The choice of start week is relevant in combination with the estimated $t_{0}$ (see below) to determine length at the first occurrence in the samples. For subsequent ages, the choice of week 12 does not imply that length growth must start in week 12. It only implies that the number of weeks from 
219 the cessation of length growth in one year to the onset of length growth in the next year

220 is 37 weeks (=52 weeks-15 weeks). Hence, length growth may start earlier than week 12

221 and cease earlier than week 27 without affecting the analyses.

222

223

225

226

227

228

229

230

231

232

233

234

235

236

237

\subsection{Identifying the effects of long term average biophysical conditions} on length at age and condition

The effect of biophysical conditions on length at age was estimated through analyses of the parameters of the von Bertalanffy growth equation based on data from the entire North Sea and ignoring any cohort effects. This method is suitable for revealing the effect of average conditions at the fishing ground (e.g. average bottom temperature at the fishing ground during the growth season) on growth in length. The relationship was analysed by first estimating a common von Bertalanffy equation for all samples (eq. 4) by

minimizing the squared deviation between observed and predicted length, $\hat{l}$, from the model:

$\hat{l}=L_{\infty}\left(1-\exp \left(-K\left(t_{g}-t_{0}\right)\right)\right)=L_{\infty}\left(1-\exp \left(-K\left(t_{a}-t_{y} t_{b}-t_{0}\right)\right)\right)$

where $L_{\infty}, K$ and $t_{0}$ are the parameters of the von Bertalanffy equation describing asymptotic length, intrinsic somatic length growth rate and the theoretical age at length 0 , respectively. A second von Bertalanffy relationship was then constructed where one of the parameters $L_{\infty}, K$ and $t_{0}$ was a second degree polynomial in one of the explanatory variables. The decrease in variation (sum of squares) incurred by including the effect of the explanatory variable was then evaluated with an F-test. This was performed for the following explanatory variables; surface temperature, bottom temperature, copepod biomass, proto-zooplankton biomass, depth, latitude, longitude and average density at 
241 the given fishing ground. All variables were normalized to range between -1 and 1 before

242 estimating the parameters to facilitate the optimisation of the model parameters in the

243 non-linear model (Zuur et al., 2009). The correlation between explanatory variables was

244 investigated to determine whether any combinations of variables exhibited high

245 collinearity. One model was then fitted for each of the combinations of a $2^{\text {nd }}$ degree

246 polynomial effect of the factors surface temperature, bottom temperature, copepod

247 biomass, proto-zooplankton biomass, depth, latitude, longitude and average density on

248 each of the parameters $L_{\infty}, K$ and $t_{0}$, a total of 24 model fits. The model with the highest

249 probability of improving the description of mean length at age was then chosen (F-test)

250 and the procedure repeated using this model as the new basic model and comparing this

251 to models adding all remaining combinations of effects one at a time. Once a second

252 degree polynomial of a particular factor had been found significant, higher degree

253 polynomials of the particular factor were also tested. Cross effects between the

254 explanatory variables were not tested with the exception of those between latitude and

255 longitude. As the objective of this analysis was to identify major sources of variation

256 rather than all sources of variation, only factors explaining more than $1 \%$ of the residual

257 variation in mean length from a common von Bertalanffy were included in the final

258 model.

259 In addition to the analyses of length at age, the relationship between average

260 condition at each fishing ground and the long term average biophysical conditions surface

261 temperature, bottom temperature, copepod biomass, proto-zooplankton biomass, depth

262 and average density at the given fishing ground was analysed. To describe a relationship

263 where condition increases with time but possibly decreases in the end, a second degree 
264 polynomial effect of the different variables was added to the model of condition as a

265 function of week:

266

$C=\operatorname{pol}_{3}($ week $)+\operatorname{pol}_{2}(x)$

Where $x$ denotes the variable investigated and $p o l_{i}(x)$ is a $i^{\text {th }}$ degree polynomial in $x$.

268 The relationship between average condition at age and week was analysed by fitting a $3^{\text {rd }}$ degree polynomial as preliminary investigations showed a plateau in this state which was poorly fitted by a $2^{\text {nd }}$ degree polynomial.

271 A joint model for all ages with a separate polynomial for the effect of week for each age group was used whereas the effect of the biophysical variable tested was the same for all ages. Similarly to the analyses of the von Bertalanffy parameters, the variable with the highest F-value was added to the model and the process rerun to examine the effect of the remaining variables (Forward elimination). Only weeks with at least 100 observations were used to assure that the effect of week was not affected by poorly sampled weeks outside the main season.

Finally, to investigate whether the samples are unbalanced with respect to the spatial

279 distribution of samples in different weeks, the average latitude and longitude of samples were estimated and the presence or absence of trends in these were derived by estimating the Pearson correlation between week and latitude and longitude, respectively.

\subsection{Changes in length and condition of sandeels accessible to the fishery}

As the emergence behaviour of sandeels can affect the length and condition of 
took place over at least 5 weeks in a season. A second degree polynomial was fitted to

287 length at age, $\hat{l}$, as a function of week $(t)$ at fishing grounds where at least 3 samples were

288 taken in each of at least 5 weeks during a season. If the second degree term of the

289 polynomial was significantly negative, the predicted length in the last week sampled was

290 compared to the confidence interval of the predicted length in the week where length

291 was predicted to be greatest. If the predicted length in the last week fell below this

292 confidence interval, a significant decrease in length late in the season was recorded. This

293 method was used rather than a non-linear model, as the non-linear model was unable to

294 estimate the saturation level. In addition to this, the residual length at age from the von

295 Bertalanffy model as a function of week of the season was investigated for trends.

296 Even if there is no difference in the fraction buried at length early and late in the

297 season, higher conditioned sandeels may have buried earlier leading to a decline in the

298 average condition of sandeels accessible to the fishery late in the season. Therefore,

299 seasonal changes in average condition were modelled using the same methodology used

300 to consider length changes. To investigate the change in condition over the course of a

301 season, condition of 1- and 2-year olds in samples from fishing grounds were examined to

302 detect decreases in length at age. Due to limited spatial coverage late in the season,

303 samples taken later than week 22 were excluded from the analysis.

\subsection{Spatio-temporal differences in weight at age}

305 Weight at age was predicted for each bank and week by estimating length and age and condition from the reduced models of length at age and condition, respectively. 
3074 Results

308

309

310

311

312

313

314

315

316

317

\subsection{Data and initial analyses}

A total of 478702 sandeel were length measured in the samples taken. Of these, age was estimated in 228 668. After eliminating samples from fishing grounds where $<5$ hauls were taken, samples from outside the main fishing season, samples from fishing grounds and weeks where age-length keys were not available as well as samples taken outside the area covered by the zooplankton data, 384175 length measurements were used to calculate a total of 3856 estimates of length at age originating from 68 fishing grounds (fig. 2, fig. 3). Of these, 54\% were length at age 1, 34\% age at length 2 and $11 \%$ length at age 3.

The length - weight relationship had the exponent $b=3.060$ (standard deviation $=0.005$ ) and the monthly average condition factors are given in table 1. A total of 38425 observations were included in the analyses and length explained 93\% of the total deviance in weight and monthly differences in average condition explained another $1.0 \%$. There was an initial increase in average condition followed by a significant decrease in July (table 1).

\subsection{Identifying the effects of long term average biophysical conditions} on length at age

By far the largest part of the variation in length was explained by the effects of latitude and longitude on $L_{\infty}$ and $K$, respectively. These factors together explained $41 \%$ of 
328 the variation in mean length at age (table 2). The final model based on the normalised 329 variables was

$\hat{l}=L_{\infty}\left(1-\exp \left(-K\left(t_{g}-t_{0}\right)\right)\right)=L_{\infty}\left(1-\exp \left(-K\left(t_{a}-t_{y} t_{b}-t_{0}\right)\right)\right)$

331 where

332

$K=0.609^{(0.032)}+0.152^{(0.014)}$ Lon-0.086 ${ }^{(0.012)} L_{o n}{ }^{2}+0.308^{(0.028)} T_{S}+0.274^{(0.033)} T_{S}^{2}$

$$
+0.073^{(0.010)} D-0.072^{(0.012)} D^{2}
$$

$L_{\infty}=17.6^{(0.22)}-0.44^{(0.23)} L a t-10.3^{(0.57)} L a t^{2}+11.9^{(1.0)} L a t^{3}+19.5^{(1.3)} L a t^{4}$

$t_{0}=-0.734^{(0.061)}$

and Lon is longitude, $T_{S}$ is surface temperature, Lat is latitude, $D$ is depth and values in parentheses denote standard error of the estimates. The response of $L_{\infty}$ and $K$ to latitude, longitude, surface temperature and depth is shown in Fig. 4. The polynomial in latitude was weakly determined at the extremes and fixing normalised latitudes to $>56.6^{\circ} \mathrm{N}$ or $<52.7^{\circ} \mathrm{N}$ improved the fit significantly and resulted in the parameters shown here. The

341 final model explained $46.9 \%$ of the total variation around a common von Bertalanffy relationship. Fish were larger in the northeast North Sea and had a higher intrinsic

343 somatic length growth rate in warm areas and areas which were not too shallow (fig. 4,

344 fig. 5). Variation in von Bertalanffy parameters associated with the minimum, median and

345 maximum observed values of the contributing factors is given in Fig. 5. Location had a 346 large effect on length at age and condition even after accounting for temperature. This

347 can be illustrated from predicted length and condition at the different sandeel grounds as 
348 a function of local latitude, longitude, surface temperature and depth, with a $10.1 \mathrm{~cm}$

349 range in length at age 1 across the grounds (fig. 6).

351 correlation>0.8): copepod biomass and proto-zooplankton biomass (correlation=0.81),

352 bottom temperature and latitude (correlation=0.89) and bottom temperature and depth

353 (correlation=-0.80). Among these factors, only latitude was included in the final model.

354 Surface temperature, longitude and sandeel density were not highly correlated to any of

355 the other variables.

almost identical to those affecting the parameters in the von Bertalanffy model of growth in length. The final model of condition included effects of week, age, latitude and sea surface temperature. Week and age explained $42 \%$ of the total variation and condition increased with latitude and sea surface temperature (latitude $r^{2}=0.054$ and sea surface temperature $\left.r^{2}=0.037\right)$. The $r^{2}$ increased by less than $1 \%$ by adding further variables. The reduced model of condition in $\mathrm{mg} / \mathrm{cm}^{3.06}$ was 
369 Condition of all ages peaked in week 20 and condition of age 1 sandeel was slightly higher 370 than that of older sandeel.

371 Average longitude of the samples showed a clear temporal pattern with a

372 significant decrease in longitude over the season (correlation $=-0.59, P=0.0197)$. The trend 373 appeared to be dome shaped rather than linear, and estimating a second degree

374 polynomial relationship between week and average longitude resulted in an $r^{2}$ of 0.82 .

375 There was no trend in average latitude of the samples over the weeks (correlation $=-0.22$,

$376 P=0.4203)$. The trend in longitude combined with the almost monotonically increasing

377 relationship between longitude and $K$ resulted in a clear dome shaped relationship

378 between predicted length in the samples and week of the season and hence a

379 relationship between age and length which appears to fluctuate around a von Bertalanffy

380 relationship (fig. 7). Mean length at age in the samples peaked around midway through

381 the season, with decreases of 1.4 and $0.9 \mathrm{~cm}$ thereafter, corresponding to 11 and $7 \%$ for

382 ages 1 and 2, respectively. This corresponds to an apparent decrease in mean weight

383 from the maximum observed of $23 \%$ and $38 \%$, respectively, at the end of the season. As

384 the model of length at age did not include any decrease in length growth late in the

385 season, this effect was entirely caused by the unbalanced sampling design of the fishery,

386 which started at higher longitudes.

\subsection{Changes in length and condition of sandeels accessible to the fishery}

Only four fishing grounds were sampled sufficiently in any one year to be included in the analyses of a late season decrease in length, and each of them only in one year (fig.

390 8). Of these, the concave second degree polynomial fitted the data significantly better 
392

393

394

395

396

400

401

402

403

404

405

406

407

408

409

410

411

412

413

was sampled markedly later in the season than the others, and this could be the reason for the absence of an effect at the other grounds. Length at age was significantly lower than the observed maximum for weeks greater than 24 for age 1 and weeks greater than 23 for age 2 . The decrease observed up to the last sampling week was $0.8 \mathrm{~cm}$ for 1 -year olds and $1.7 \mathrm{~cm}$ for 2-year olds, corresponding to 6 and 13\%, respectively (fig. 8).

Condition was a significantly concave function of week $(\mathrm{P}<0.05)$ for all ages at all banks except for age 1 at Southernmost Rough and age 2 at Berwick Bank and Stendysse $(P>0.25)$ (fig. 9). The condition at age 2 on $N$. W. Rough reached a plateau from which it did not decrease significantly while condition at age 1 decreased significantly from week 21 onwards, in total exhibiting a decrease in condition of $15 \%$. The samples in which the decrease in condition at Berwick Bank was recorded were obtained after week 22 exhibiting a decrease in condition of 12 and 13\%, for ages 1 and 2 respectively. Condition in the remaining cases increased monotonically with week until week 21 (fig. 9). Across the four banks, condition appeared to increase from values as low as $2.0 \mathrm{mg} \bullet \mathrm{cm}^{-3.06}$ until a peak value of 3.2-3.5 $\mathrm{mg} \bullet \mathrm{cm}^{-3.06}$ was attained around week 20-22 (late May - early June), corresponding to more than $160 \%$ of that recorded at the beginning of the season. Together with the observed decrease in mean length late in the season, the decrease in condition of individuals accessible to the fishery resulted in a predicted decrease in mean weight of $34 \%$ and $15 \%$ in age 1 sandeel at Berwick bank and N. W. Rough, respectively and of $64 \%$ in age 2 sandeel at Berwick Bank, corresponding to $4.9 \%$ per week and 3.8\% per week in age 1 sandeel at Berwick bank and N. W. Rough, respectively and $9.1 \%$ per week in age 2 sandeel. The remaining 5 combinations of fishing 
414 ground and age showed no significant decrease in mean length or condition late in the

415 season and hence no decrease in mean weight at age.

\subsection{Spatio-temporal differences in weight at age}

Weight at age varied considerable both spatially and temporally. Weight at age 2 in week 21 varied 4-fold between locations in the North Sea (4.6 to $19.0 \mathrm{~g}$ ), corresponding to 216 to 53 age 2 sandeel per $\mathrm{kg}$. Within a specific location, weight at age varied from the beginning to the end of the season, but the variation was substantially less than the spatial variation. For example, mean weight at age 1 and 2 increased by $90 \%$ and $65 \%$, respectively, from week 13 to 20 at N. W. Rough, corresponding to 2641 -year olds sandeel in week 13 compared to 139 in week 20.

\section{Discussion}

Whilst the existence of spatial differences in growth rate of lesser sandeel within the North Sea has been reported previously (Macer, 1966; Bergstad et al., 2002; Wanless et al., 2004; Boulcott et al., 2007), the present study provides the most comprehensive view of regional variability in any sandeel species. Sandeel grew faster at eastern locations, at high temperatures and at greater depths and the asymptotic length and condition both increased towards northern sandeel banks. Further, condition was higher at warmer fishing grounds. While a few instances of lower length or condition at age late in the season were recorded, the regional differences in length at age combined with the spatio-temporal distribution of the fishery were sufficient to explain the dome-shaped relationship between length and week of the year. No further sign of dome shaped patterns could be seen in the residuals from the model. Weight at age varied considerably and spatial and temporal differences resulted in 4 fold and 1.9 fold variation in the 
437 number of sandeels required to obtain a specific weight, respectively. Hence, unless

438 handling time differs substantially between sandeel size groups, the energy value of

439 sandeel as prey to predators varies considerably.

Temperature had a large positive effect on $K$ while there was no effect on

asymptotic length or $t_{0} . K$ in the original theoretical foundation of the von Bertalanffy

442 equation is directly proportional to standard metabolic rate, a factor known to increase exponentially with temperature (Behrens et al., 2007). As temperature influences the emergence of sandeels (Winslade, 1974b; van der Kooij et al., 2008), feeding activity (Winslade, 1974b) and the scope for growth, this factor may be expected to explain a large component of length-at-age variability. Average copepod and proto-zooplankton biomass and average density at the given fishing ground did not affect length or condition at age. However, this may reflect the fact that standing biomass alone is not the determining factor, as also duration, production and timing of the feeding period relative to peak zooplankton abundance plays a role. For example, copepod biomass tends to peak later and for a shorter period in the north western North Sea than in the north east North Sea (Fransz et al. 1991), corresponding with the low and high growth areas for sandeel. Condition of age 1 sandeel was slightly higher than that of older sandeel. This matches their higher energy requirements during the overwintering phase (van der Kooij et al. 2008, van Deurs et al. 2011). burying through to week 22 as only $25 \%$ and $33 \%$ of the relationships between week and length and week and condition, respectively, were significantly decelerating. The decrease in mean length and weight at age over the season observed here and in 
460 Pedersen et al. 1999 was therefore largely a result of changes in the distribution of the

461 fishery from the early exploitation of the central and eastern banks, where mean length is

462 large, to the later fishery on western grounds, where mean length is smaller (fig. 6). The

463 low occurrence of decreases in mean condition late in the season is in contrast with

464 results on mean weights on some grounds reported by Bergstad et al. (2002) and Wanless

465 et al. (2004). However, these studies reported the decrease to commence around

466 midsummer, which approximately marks the end of the sampling period in this study. The

467 decrease in length and condition observed at Berwick Bank after week 22 and the lack of

468 any increase in length of age 2 sandeels at 2 of the 4 grounds examined could be

469 consistent with these local studies. Hence, it is possible that size differentiated burying

470 takes place after mid-summer.

471 The length of the growth season for the three grounds with sufficient data yielded a

472 combined average of 15 weeks, although this may be linked to their close geographic

473 proximity. If length of the season varies geographically, it is possible that part of the

474 effect recorded on the von Bertalanffy parameters is caused by effects on the length of

475 the growth season rather than effects on $K$ and $L_{\infty}$. Estimation of season length at other

476 fishing grounds would provide information on the range of values exhibited by this

477 parameter and would improve the estimates of local parameters.

478 The von Bertalanffy parameters reported here are determined from average length

479 in the catches at consecutive points in time and therefore are only estimates of the actual

480 length growth rate of individual sandeel if catchability is independent of length and

481 mortality is not size related within a given age group, time and place. Catchability of

482 sandeel is determined by the selectivity of the gear and the coincidence between 
483 sandeels in the water column and the path of the gear (Hilborn and Walters 1992).

484 Sandeel fisheries operate with very small mesh sizes and it seems unlikely that there will

485 be major length differences in catchability within the path of the gear. However, there is a 486 possibility for mean lengths to be affected by length differences in horizontal distribution.

487 If the sandeel move into the fishing ground as they grow, this will tend to depress length 488 growth rates estimated from mean lengths (Jensen et al., 2011). However, such a

489 depression should be evident by a mismatch between the length of individuals at the end 490 of a season and the length of individuals of the same age in years at the beginning of the

491 subsequent season as large fish will be overrepresented in the beginning of the season.

492 This was not observed here and there was generally a good agreement between length at 493 age 1 in the end of the growth season and length at age 2 in the beginning of the season 494 the subsequent year, as demonstrated by the estimated season length which depended 495 on the close correspondence between length at the end of the seasons and in the 496 beginning of the subsequent season (supplementary material). Mortality of fish prey is often reported to be size dependent (Ursin, 1973; Cook, 2004). However, though such size dependence would affect the parameters estimated, it 499 is unlikely to explain the differences in length at age between north and south and low 500 and high temperature areas reported in this study. For this to be the case, the predation 501 on large sandeel should be lower in the northern-eastern North Sea and in areas of high surface temperature. This seems unlikely as the abundance of both gadoids and mackerel 503 is highest in the northern North Sea (Cunningham et al., 2007; Lewy and Kristensen, 2009) 504 and consumption by predatory fish should be positively related to temperature within the 505 range observed here. 
507 to local productivity, as fecundity is related to weight at age (Gauld and Hutcheon, 1990;

508 Boulcott and Wright, 2008; Boulcott and Wright, 2011) and fast growing A. marinus can mature a year earlier (Boulcott et al., 2007). Sandeel near the UK coast, such as at

510 Berwick Bank, were shorter at age than other aggregations and this partly explains why

511 few age 2 were found to mature in this area (Boulcott et al., 2007). Conversely, sandeel at

512 banks in the north eastern North Sea appear to grow rapidly and some are able to mature 513 as young as age 1 (Boulcott et al., 2007).

515 Sea than in north-western areas. Weight at age 2 in week 21 varied 4-fold between

516 locations in the North Sea. The variation in temporal weight was substantially less than

517 the spatial variation. For example, mean weight at age 1 and 2 increased by $90 \%$ and $65 \%$,

518 respectively, from week 13 to 20 at N. W. Rough. A predator which captures each sandeel

519 individually therefore experiences poorer energetic returns in the north-western North

520 Sea than in other areas, an effect that may be aggravated by higher energy density of high

521 condition fish. This is likely to make predators in the north-western North Sea particularly

522 sensitivity to changes in sandeel abundance. This is in accordance with both the general

523 level and the annual variation of kittiwake breeding success, which is high and stable in

524 eastern English colonies but low and highly variable in eastern Scottish colonies

525 (Frederiksen et al., 2005). If this relationship is extrapolated, single load predators of

526 sandeel may be expected to experience problems in the far south part of the North Sea as

527 well. 


\section{Conclusions}

Whilst the existence of spatial differences in growth rate of lesser sandeel

530 within the North Sea has been reported previously (Macer, 1966; Bergstad et al., 2002;

531 Wanless et al., 2004; Boulcott et al., 2007), the present study provides the most

532 comprehensive view of regional variability in any sandeel species. Sandeel grew faster at

533 north-eastern and central locations, at high temperatures and at greater depths and the

534 asymptotic length and condition both increased towards northern sandeel banks. Further,

535 condition was higher at warmer fishing grounds. While a few instances of lower length or

536 condition at age late in the season were recorded, the regional differences in length at

537 age combined with the spatio-temporal distribution of the fishery were sufficient to

538 explain the dome-shaped relationship between length and week of the year. Hence, the

539 results clearly show the danger of making assumptions on the biology of a species based

540 on a biased sampling design. Weight at age varied considerable and spatial and temporal

541 differences resulted in 4 fold and 1.9 fold variation in the number of sandeels required to

542 obtain a specific weight, respectively. Hence, the value of sandeel as prey to single load

543 predators varies considerably with values in central and north-eastern North Sea being

544 substantially higher than in north-western and southern areas.

\section{Acknowledgements}

547 This work has received funding from the Danish strategic research project 'SUNFISH' and

548 from the European Community's Seventh Framework Programme (FP7/2007-2013) under

549 Grant Agreement No. 266445 for the project Vectors of Change in Oceans and Seas 
550 Marine Life, Impact on Economic Sectors (VECTORS). P. Wright was supported by the

551 Scottish Government project ST007. We are deeply grateful to the fishing skippers who

552 collected the data and placed them at our disposal, to Stina B. S. Hansen, Nina Fuglsang

553 and the laboratory assistants who worked up the thousands of length samples and age

554 determined an immense number of otoliths and to Josefine Egekvist for mapping.

\section{$555 \quad 7 \quad$ References}

556 Behrens, J.W., Stahl, H.J., Steffensen, J.F., Glud, R.N., 2007. Oxygen dynamics around

557 buried lesser sandeels Ammodytes tobianus (Linnaeus 1785): mode of ventilation and

558 oxygen requirements. J. Exper. Biol. 210, 1006-1014.

559 Bergstad, O.A., Høines, Å.S., Jørgensen, T., 2002. Growth of sandeel, Ammodytes marinus, 560 in the northern North Sea and Norwegian coastal waters. Fish. Res. 56, 9-23.

561 Boulcott, P., Wright, P.J., 2008. Critical timing for reproductive allocation in an over-

562 wintering capital breeder: experimental evidence from sandeels. Aquat. Biol. 3, 31-40.

563 Boulcott, P., Wright, P. J., 2011. Variation in fecundity in the lesser sandeel: implications

564 for regional management. J. Mar. Biol. Ass. 91, 1273-1280.

565 Boulcott, P., Wright, P.J., Gibb, F.M., Jensen, H., Gibb, I.M., 2007. Regional variation in the 566 maturation of sandeels in the North Sea. ICES J. Mar. Sci. 64, 369-376.

567 Brett, J.R., 1979. Environmental factors and growth, in: Hoar, W. S., Randall, D. J., Brett, J.

568 R. (Eds.), Fish Physiology. Academic Press, New York and London, pp. 599-675.

569 Cook, R.M., 2004. Estimation of the age-specific rate of natural mortality for Shetland sandeels. ICES J. Mar. Sci. 60, 159-164. 
571 Coull, K.A., Jermyn, A.S., Newton, A.W., Henderson, G.I., Hall., W.B., 1989. Length/weight

572 relationships for 88 species of fish encountered in the North East Atlantic. Scott. Fish. Res.

573 Rep., 43.

574 Cunningham, C.L., Reid, D.G., McAllister, M.K., Kirkwood, G.P., Darby, C.D., 2007. A

575 Bayesian state-space model for mixed-stock migrations, with application to Northeast

576 Atlantic mackerel Scomber scombrus. Afric. J. Mar. Sci. 29, 347-367.

577 Daan, N., Bromley, P.J., Hislop, J.R.G., Nielsen, N.A., 1990. Ecology of North Sea fish. Neth. $578 \quad J$. Sea Res. 26. 343-386.

579 Elliot, A.J., Clarke, T., Li, Z., 1991. Monthly distributions of surface and bottom

580 temperatures in the northwest European shelf seas. Cont. Shelf Res. 11, 453-466.

581 Engelhard, G. H., Peck, M. A., Rindorf, A., Smout, S. C., van Deurs, M., Raab, K., Andersen,

582 K. H., Garthe, S., Lauerburg, R., Scott, F., Brunel, T., Aarts, G., van Kooten, T., Dickey-

583 Collas, M. 2014. Forage fish, their fisheries, and their predators: who drives whom? ICES J.

584 Mar. Sci. 71, 90-104.

585 Fransz, H. G., Colebrook, J. M., Gamble, J., and Krause, M. 1991. The Zooplankton of the 586 North Sea. Neth. J. of Sea Res., 28, 1-52.

587 Frederiksen, M., Wright, P. J., Harris, M. P., Mavor, R. A., Heubeck, M., Wanless, S. 2005.

588 Regional patterns of kittiwake Rissa tridactyla breeding success are related to variability 589 in sandeel recruitment. Mar. Ecol. Progr. Ser. 300, 201-211.

590 Furness, R.W., 1990. A preliminary assessment of the quantities of Shetland sandeels

591 taken by seabirds, seals, predatory fish and the industrial fishery in 1981-1983. Ibis 132, 
593 Gauld, J.A., 1990. Movements of lesser sandeels (Ammodytes marinus Raitt) tagged in the 594 northwestern North Sea. J. Cons. Int. Explor. Mer. 46, 229-231.

595 Gauld, J.A., Hutcheon, J.R., 1990. Spawning and fecundity in the lesser sandeel, 596 Ammodytes marinus Raitt, in the north-western North Sea. J. Fish Biol. 36, 611-613.

597 Gürkan, Z., Christensen, A., Maar, M., Møller, E.F., Madsen, K.S., Munk, P., Mosegaard, H., 598 2013. Spatio-temporal dynamics of growth and survival of Lesser Sandeel early life-stages 599 in the North Sea: Predictions from a coupled individual-based and hydrodynamic600 biogeochemical model. Ecol. Model. 250, 294-306.

601 Harris, R.P., Wiebe, P.H., Lenz, J., Skjoldal, H.R., Huntley, M., 2000. ICES zooplankton 602 methodology manual. Academic Press, London

603 Hilborn, R., Walters, C.J. 1992. Quantitative fisheries stock assessment: choice, dynamics 604 and uncertainty. Chapman and Hall, New York, pp. 175-177.

605 Hislop, J.R.G., Harris, M.P., and Smith, J.G.M. 1991. Variation in the calorific value and 606 total energy content of the lesser sandeel (Ammodytes marinus) and other fish preyed on 607 by seabirds. J. Zool. 224, 501-517.

608 ICES 1995. Report of the ICES workshop on sandeel otolith analysis. ICES CM 1995/G:4

609 ICES 2006. Report of the sand eel otolith ageing workshop.

610 http://www.ices.dk/community/Documents/PGCCDBS/ReportSandEelAgeWK0906.pdf

611 ICES 2014. Report of the Herring Assessment Working Group for the Area South of 62N.

612 ICES CM 2014/ACOM:06 
613 Jensen, H., Rindorf, A., Wright, P.J., Mosegaard, H., 2011. Inferring the location and scale

614 of mixing between habitat areas of lesser sandeel through information from the fishery.

615 ICES J. Mar. Sci. 68, 43-51.

616 Jobling, M. 1985. Growth, in: Tytler, P., Calow, P. (Eds.) Fish energetics: new perspectives.

617 Croom Helm London, pp 213-229.

618 Kleine, E., 1994. Das operationelle Modell des BSH feur Nordsee und Ostsee, Konzeption

619 und Uebersicht. Bundesamt für Seeschifffahrt und Hydrographie, Technical Report,

620 Hamburg, Germany

621 Kunzlik, P.A., Gauld, J.A., Hutcheon, J.R., 1986. Preliminary results of the Scottish sandeel

622 tagging project. ICES Document CM 1986/G:7

623 Le Cren, E. D., 1951. The length-weight relationship and seasonal cycle in gonad weight

624 and condition in the perch (Perca fluviatilis). J. Anim. Ecol. 20, 201-219.

625 Lewy, P., Kristensen, K., 2009. Modeling the distribution of fish accounting for the spatial

626 correlation and overdispersion. Can. J. Fish. Aquat. Sci. 66, 1809-1820.

627 Maar, M., Larsen, J., Møller E.F., Madsen K.S., Wan Z., She J., Jonasson L., Neumann, T.,

628 2011. Ecosystem modelling across a salinity gradient from the North Sea to the Baltic Sea.

629 Ecol. Model. 222, 1696-1711.

630 Maar, M., Rindorf, A., Møller, E. F., Christensen, A., Madsen, K. S., van Deurs, M., 2014.

631 Zooplankton mortality in 3D ecosystem modelling considering variable spatial-temporal

632 fish consumptions in the North Sea. Progr. Oceanogr. 124, 78-91. 
633 Macer, C.T., 1966. Sand eels (Ammodytidae) in the south-western North Sea, their biology

634 and fishery. Fisheries Investigations, Series 2: Sea Fisheries, Ministry of Agriculture,

635 Fisheries and Food, London, 24. 55 pp.

636 Monaghan, P. 1992. Seabirds and sandeels: the conflict between exploitation and

637 conservation in the northern North Sea. Biodiv. Cons. 1, 98-111.

638 Pedersen, S.A., Lewy, P., Wright, P., 1999. Assessments of the lesser sandeel (Ammodytes

639 marinus) in the North Sea based on revised stock divisions. Fish. Res. 41, 221-241.

640 Pörtner, H.O., Rainer, K., 2007. Climate change affects marine fishes through the oxygen

641 limitation of thermal tolerance. Science 315, 95-97.

642 Rindorf, A., Lewy, P., 2001. Analyses of length and age distributions using continuation-

643 ratio logits. Can. J. Fish. Aquat. Sci. 58, 1141-1152.

644 Rindorf, A., Wanless, S., Harris, M. P. 2000. Effects of changes in sandeel availability on

645 the reproductive output of seabirds. Mar. Ecol. Progr. Ser. 202, 241-252.

646 She, J., Berg, P., Berg, J., 2007. Bathymetry impacts on water exchange modelling through

647 the Danish Straits. J. Mar. Sys. 65, 450-45.

648 Stephens, D. W., Krebs, J. R. 1986. Foraging theory. Princeton, NJ: Princeton Univ. Press.

649 Ursin, E., 1973. On the prey size preferences of cod and dab. Medd. Danmarks Fisk. Hav.

$650 \quad 7,85-98$.

651 van der Kooij, J., Scott, B.E., Mackinson, S., 2008. The effects of environmental factors on

652 daytime sandeel distribution and abundance on the Dogger Bank. J. Sea Res. 60, 201-209. 
653 van Deurs, M., Hartvig, M, Steffensen, J.F., 2011. Critical threshold size for overwintering 654 sandeels (Ammodytes marinus), Mar. Biol. 158, 2755-2746.

655 van Deurs, M., Koski, M., Rindorf, A., 2014. Does copepod size determine food

656 consumption of particulate feeding fish? ICES J. Mar. Sci. 71, 35-43.

657 Wanless, S., Wright, P. J., Harris, M. P., Elston, D. A., 2004. Evidence for decrease in size of 658 lesser sandeels Ammodytes marinus in a North Sea aggregation over a 30-yr period. Mar. 659 Ecol. Progr. Ser. 279, 237-246.

660 Wanless, S., Harris, M. P., Redman, P., Speakman, J. R. 2005. Low energy values of fish as 661 a probable cause of a major seabird breeding failure in the North Sea. Mar. Ecol. Progr. 662 Ser. 294, 1-8.

663 Winslade, P., 1974a. Behavioural studies of the lesser sandeel Ammodytes marinus (Raitt) 664 II. The effect of light intensity on activity. J. Fish Biol. 6, 577-586.

665 Winslade, P., 1974b. Behavioural studies on the lesser sandeel Ammodytes marinus 666 (Raitt). III. The effect of temperature on activity and the environmental control of the 667 annual cycle of activity. J. Fish Biol. 6, 587-599.

668 Wright, P.J., 1993. Otolith microstructure of the lesser sandeel, Ammodytes marinus. J. 669 Mar. Biol. Ass. UK 73, 245-248.

670 Wright, P.J., 1996. Is there a conflict between sandeel fisheries and seabirds? A case study 671 at Shetland. S.P.R. Greenstreet, and M.L. Tasker (Eds.), Oxford, Fishing News Books, 672 Blackwell Science, pp. 154-165. 
673 Wright, P.J., Jensen, H., Tuck, I., 2000. The influence of sediment type on the distribution

674 of the lesser sandeel, Ammodytes marinus. J. Sea Res. 44, 243-256.

675 Zuur, A.F., leno, E.N., Elphick, C.S., 2009. A protocol for data exploration to avoid common

676 statistical problems. Methods in Ecology and Evolution, 1: 3-14. DOI: 10.1111/j.2041-

$677 \quad 210 \times .2009 .00001 . x$

678 
679 Tables

680 Table 1 . Monthly average condition (only months with more than 1000 observations 681 included).

Month $\quad 10^{3 *} C_{m}\left(\mathrm{~g} / \mathrm{cm}^{3.06}\right)$

March $2.32(2.25-2.39)$

April $\quad 2.71(2.65-2.76)$

May $\quad 3.10(3.03-3.17)$

June $\quad 3.04(2.98-3.11)$

July $\quad 2.83(2.74-2.92)$

682 
683

684 Table 2. Effects of local average factors on von Bertalanffy parameters. Proportion of 685 residual variation in mean length explained by each factor (forward selection). Only 686 factors explaining at least $1 \%$ of the residual variation were included. All factors were 687 highly significant $(\mathrm{P}<0.0001)$.

\begin{tabular}{lcccc}
\hline Variable & Effect on & $F(d f 1, d f 2)$ & $r^{r}$ & Cummulated $^{r}$ \\
& parameter & & \\
& & & & \\
\hline Longitude & $K$ & $570(2,3854)$ & 0.228 & 0.228 \\
Latitude & $L_{\infty}$ & $597(6,3848)$ & 0.183 & 0.411 \\
Surface temperature & $K$ & $95(2,3846)$ & 0.028 & 0.439 \\
Depth & $K$ & $109(2,3844)$ & 0.030 & 0.469
\end{tabular}

688 


\section{Figure captions}

690 Fig. 1. Maps of biophysical variables used in spatial analyses. Depth (A), sea surface

691 temperature (B), proto-zooplankton (C) and copepods (D).

692 Fig. 2. Sampling locations (x), fishing grounds (grey polygons) and named fishing grounds

693 (text) referred to in the study.

694 Fig. 3. Length as a function of growth age.

695 Fig. 4. Predicted effect of latitude on $L_{\infty}(\mathrm{A})$, longitude on $K(B)$, sea surface temperature 696 on $K(C)$ and depth on $K(D)$.

697 Fig. 5. Effect of longitude (A, effect on $K)$, latitude (B, effect on $\left.L_{\infty}\right)$, sea surface

698 temperature $(C$, effect on $K)$ and depth (D, effect on $K)$ on length at age. Length at age 699 predicted at maximum (solid), minimum (hatched) and at midways between maximum 700 and minimum (at a value of (maximum-minimum)/2, hatch-dot). Black lines refer to the 701 estimated length, grey lines to the $95 \%$ confidence interval of the estimate.

702

Fig. 6. Maps of predicted length at each ground in week 21 at age 1 (A), 2 (B) and 3 (C) and predicted condition at age 1 in week 21 (D). Shading indicates mean length and condition, respectively, white indicating the lowest level and black the highest. Minimum length at age 1, 2 and 3: 7.0, 12.1 and $13.1 \mathrm{~cm}$, respectively. Maximum length at age 1,2 and 3: $17.1,19.5$ and $21.2 \mathrm{~cm}$, respectively.

Fig. 7. Predicted length as a function of growth age estimated from the final von Bertalanffy model (A) and residual from predicted length as a function of growth age (B).

709 The von Bertalanffy model used to predict length does not include a decrease in length growth rate over the season and the apparent drop in length from the middle of the 
711 season is entirely driven by changes in spatial distribution of the fishery. Line indicates

712 average predicted length per week over the entire data set $(A)$ and a second degree

713 polynomial (B).

714 Fig. 8. Development in length at age as a function of week at N. W. Rough in 2006 (A),

715 Berwick Bank in 2003 (B), Southernmost Rough in 2006 (C) and Stendysse in 2003 (D). Age

7161 (solid diamonds) and 2 (open triangles). Solid line is a second degree polynomial,

717 hatched lines are $95 \%$ confidence limits of the mean.

718 Fig. 9. Development in average condition factor over the season. Condition at age 1 (solid

719 diamonds) and 2 (open triangles) as a function of week at N. W. Rough in 2006 (A),

720 Berwick Bank in 2003 (B), Southernmost Rough in 2006 (C) and Stendysse in 2003 (D).

721 Solid line is a $2^{\text {nd }}$ degree polynomial of age 1 , long dash a $2^{\text {nd }}$ degree polynomial of age 2

722 and hatched lines are $95 \%$ confidence limits of the mean. 

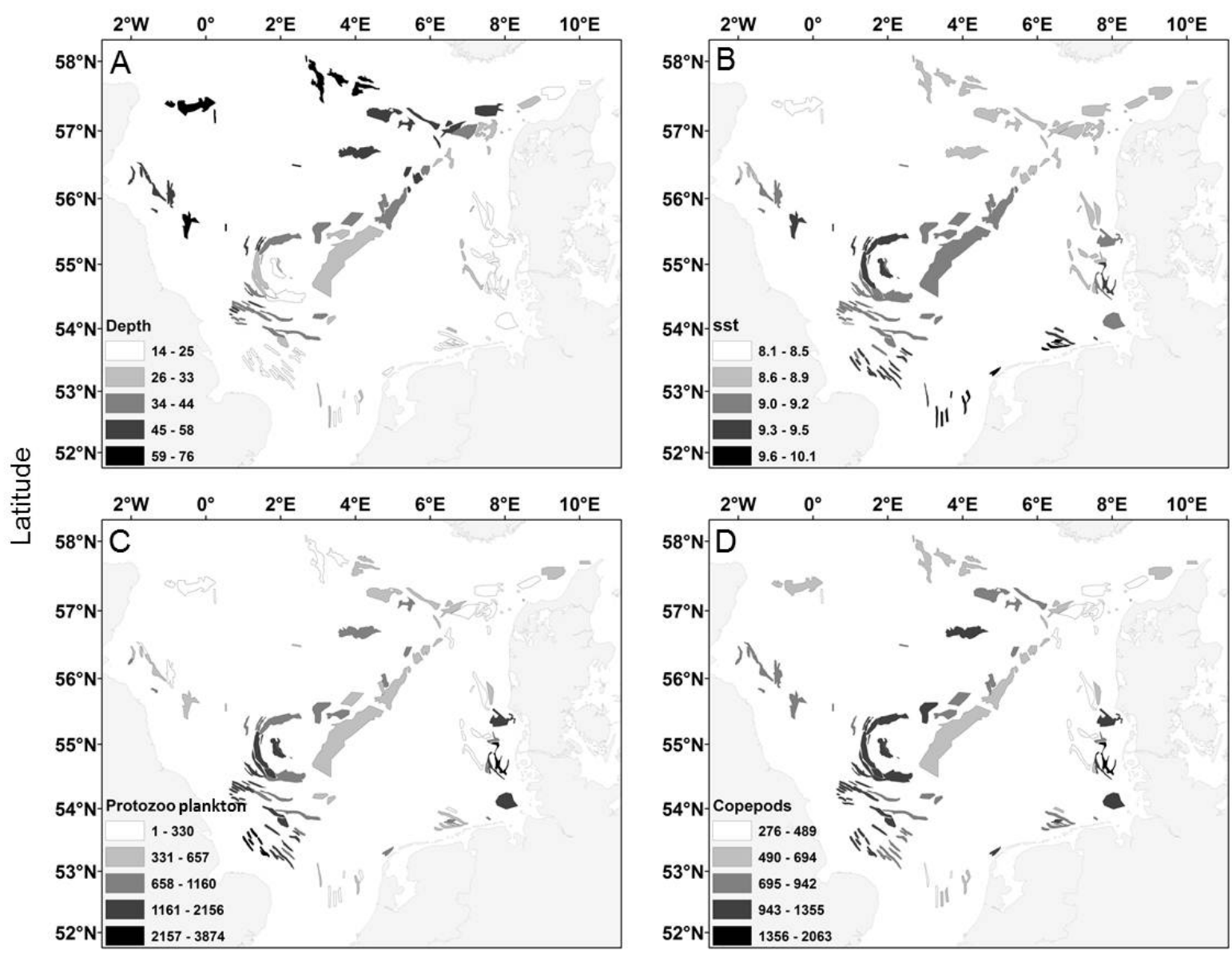

Longitude

Fig 1

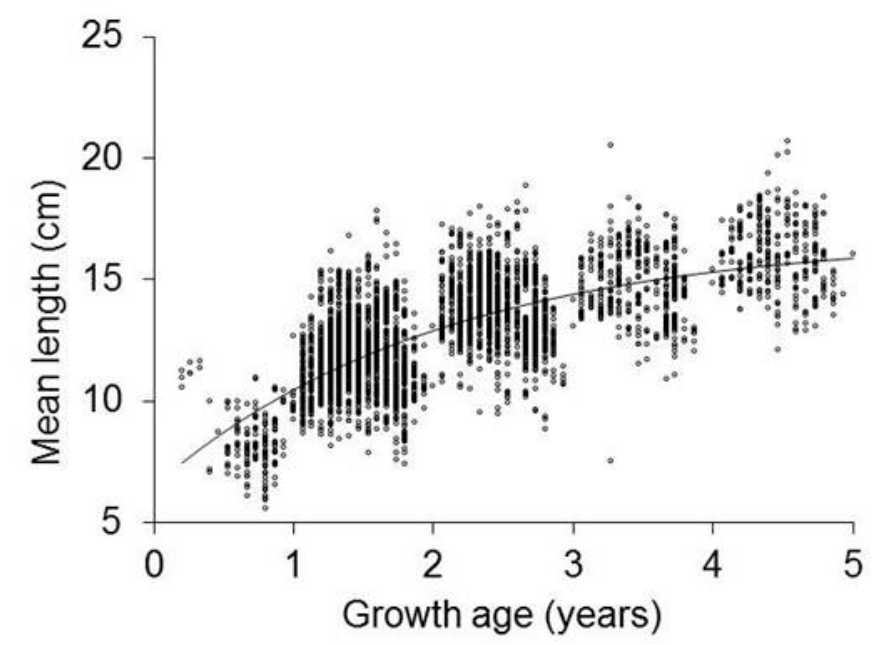

Fig. 2 


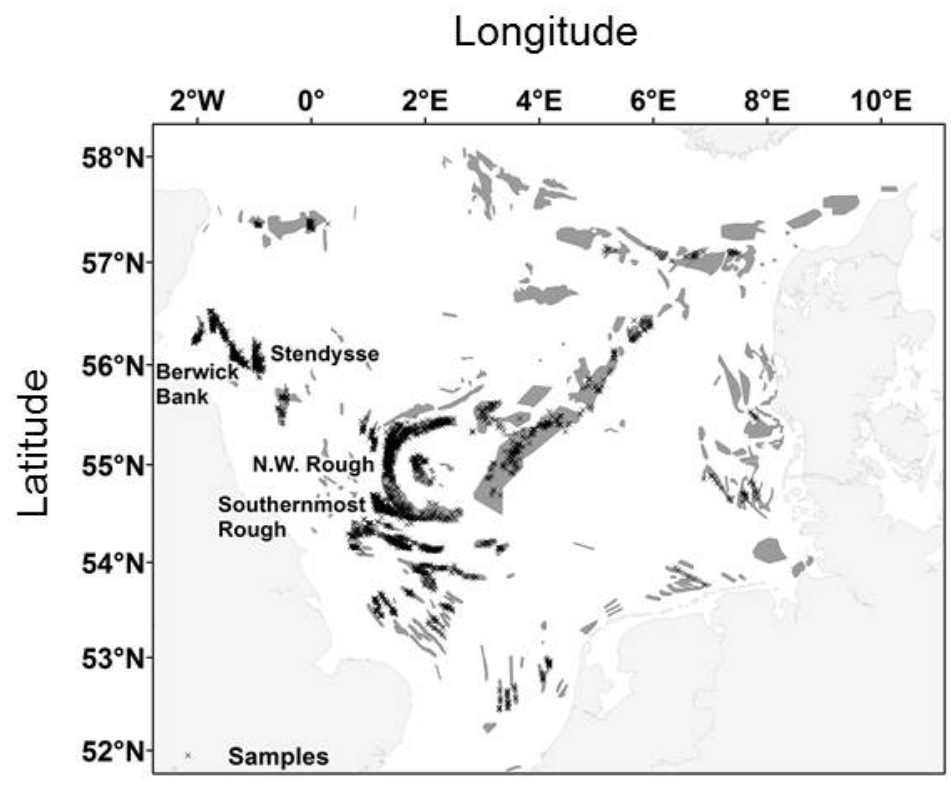

Fig. 3 

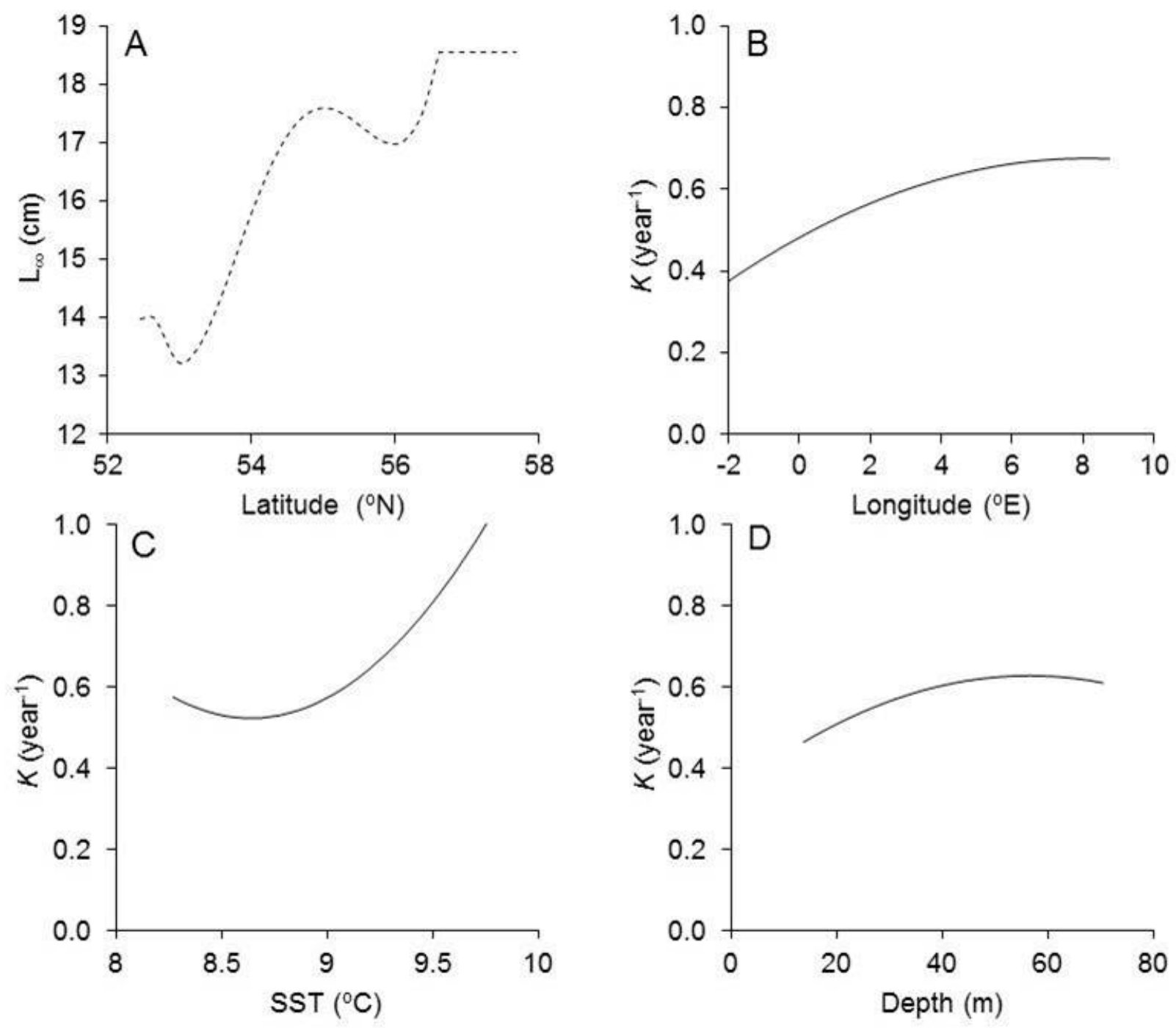

Fig. 4 


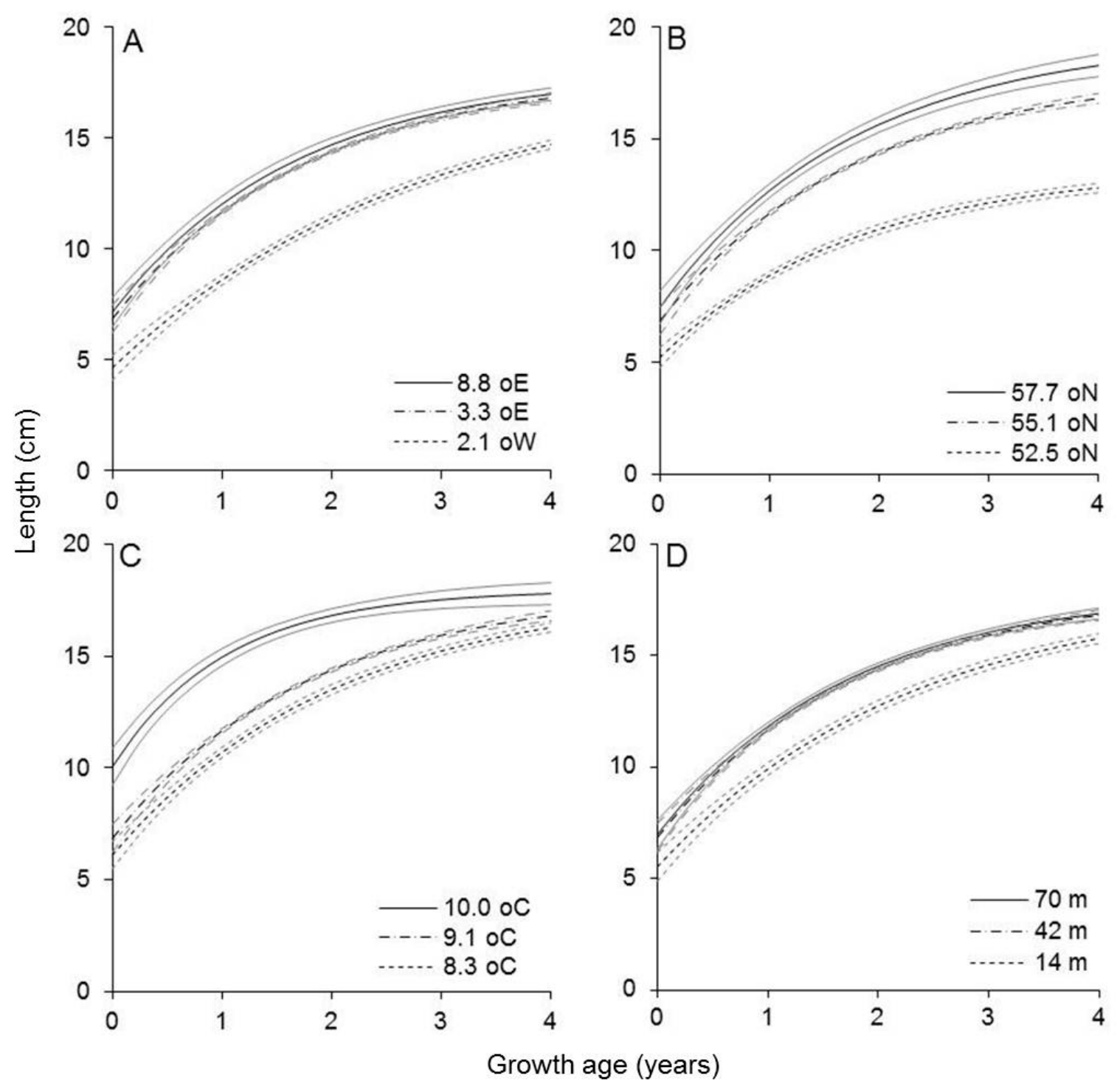

Fig. 5. 


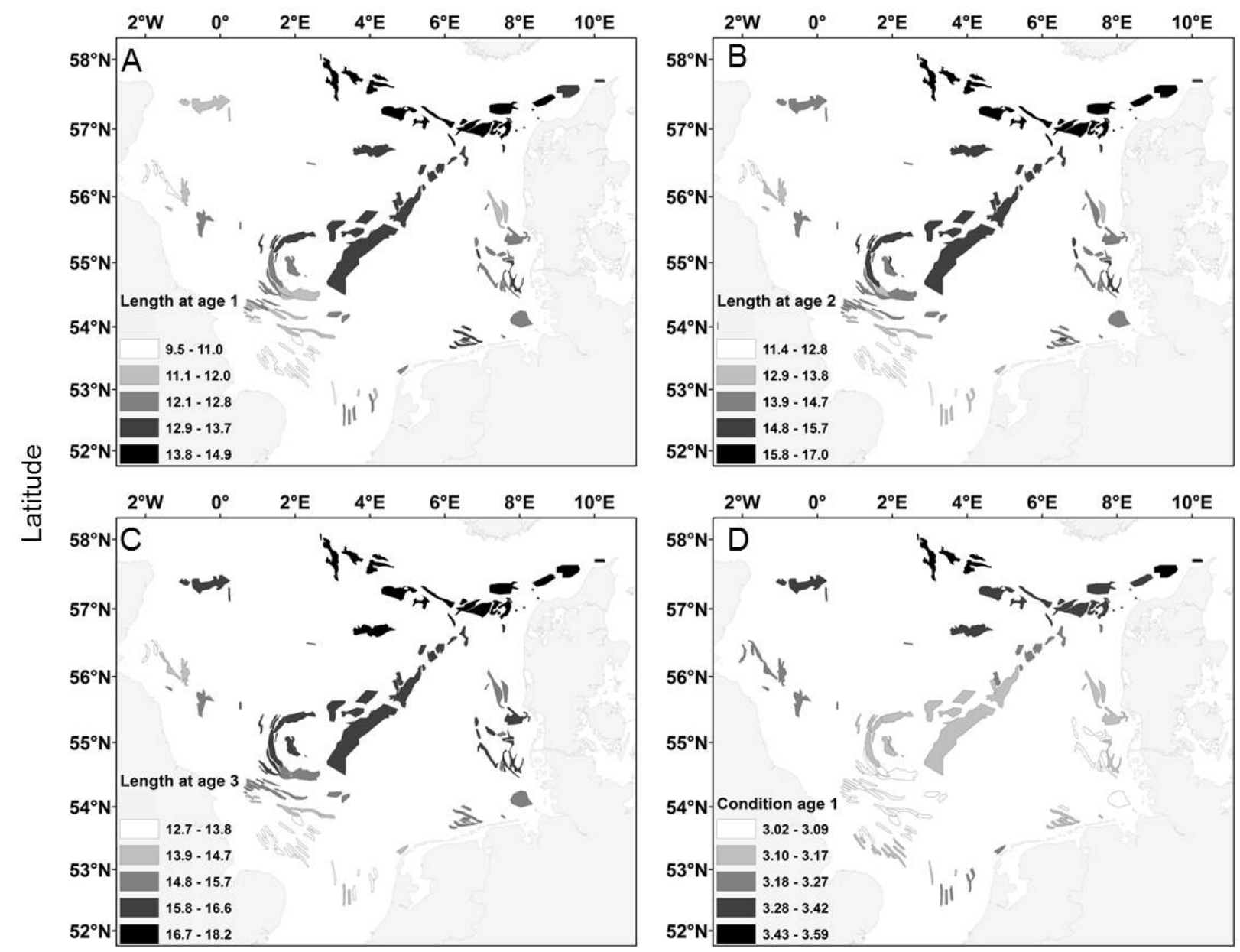

Longitude

Fig. 6.
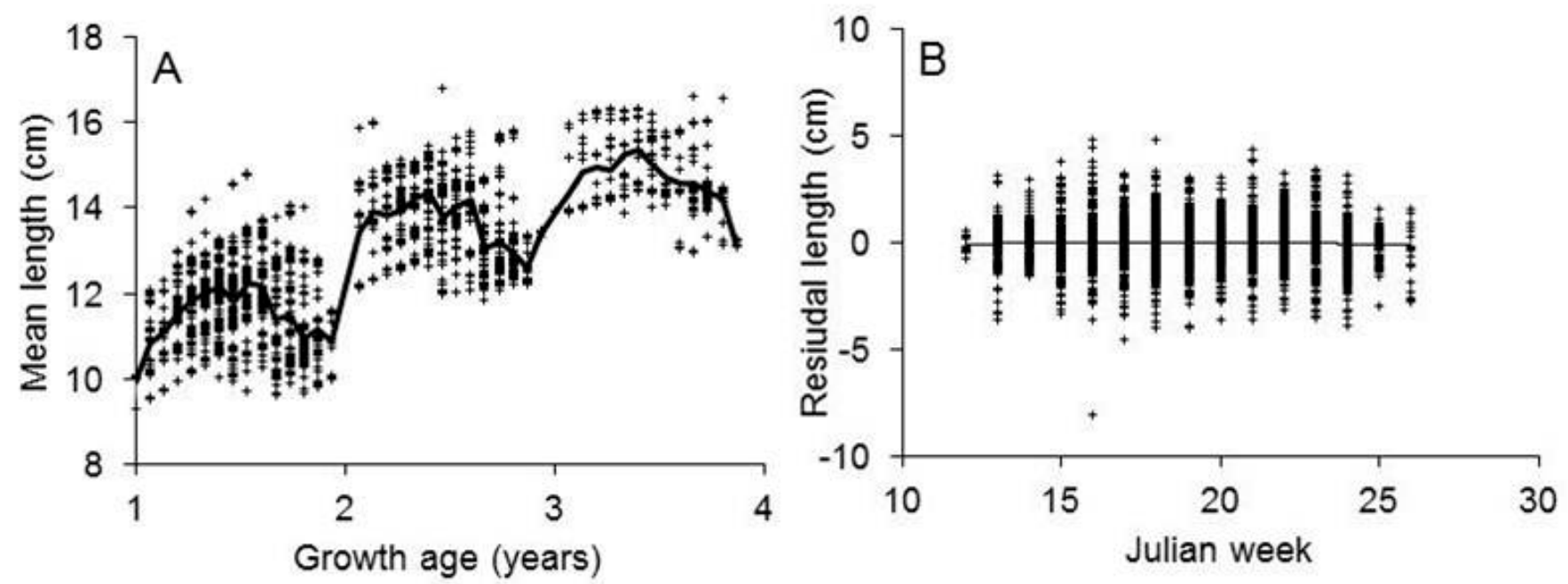

Fig. 7 

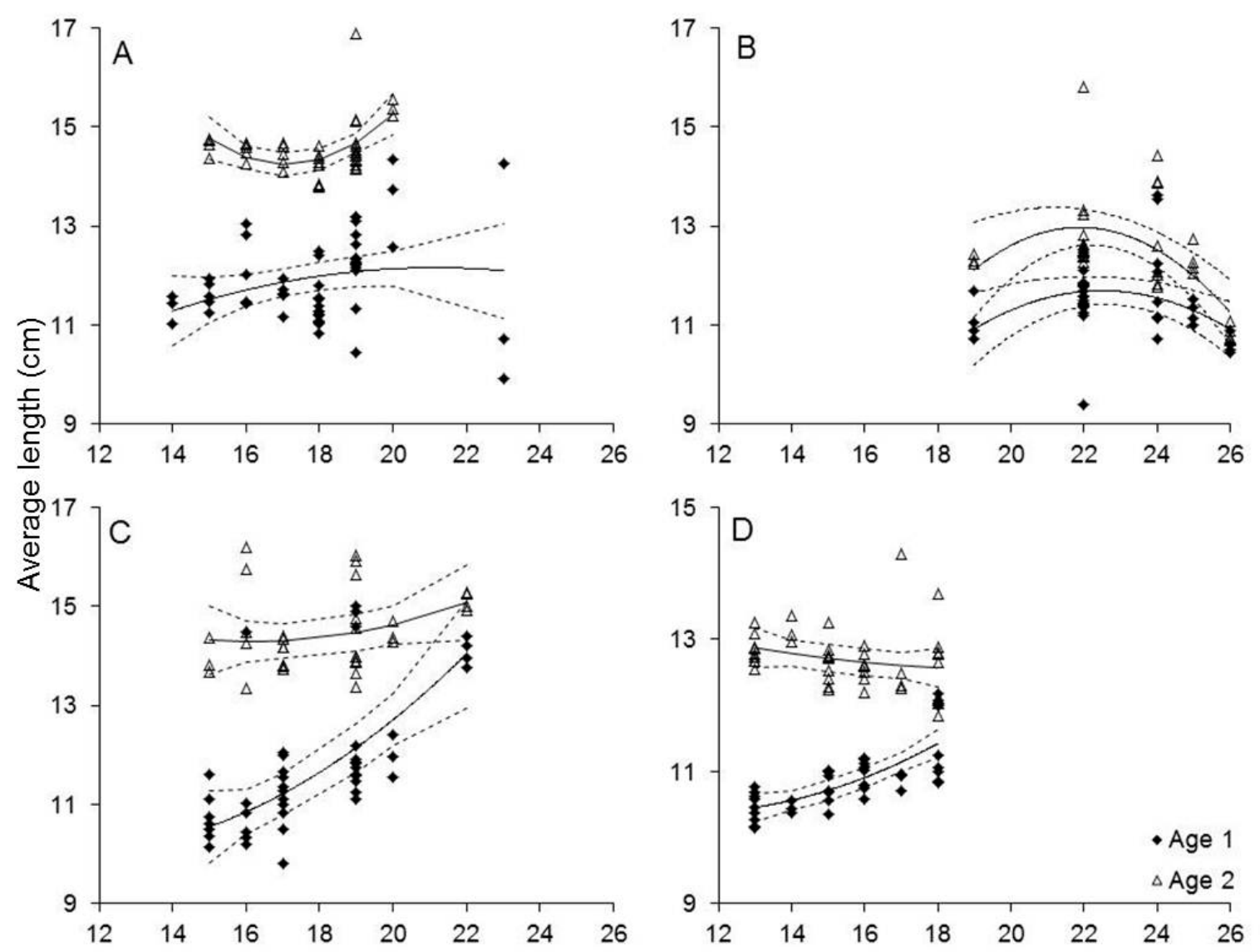

Week

Fig. 8. 

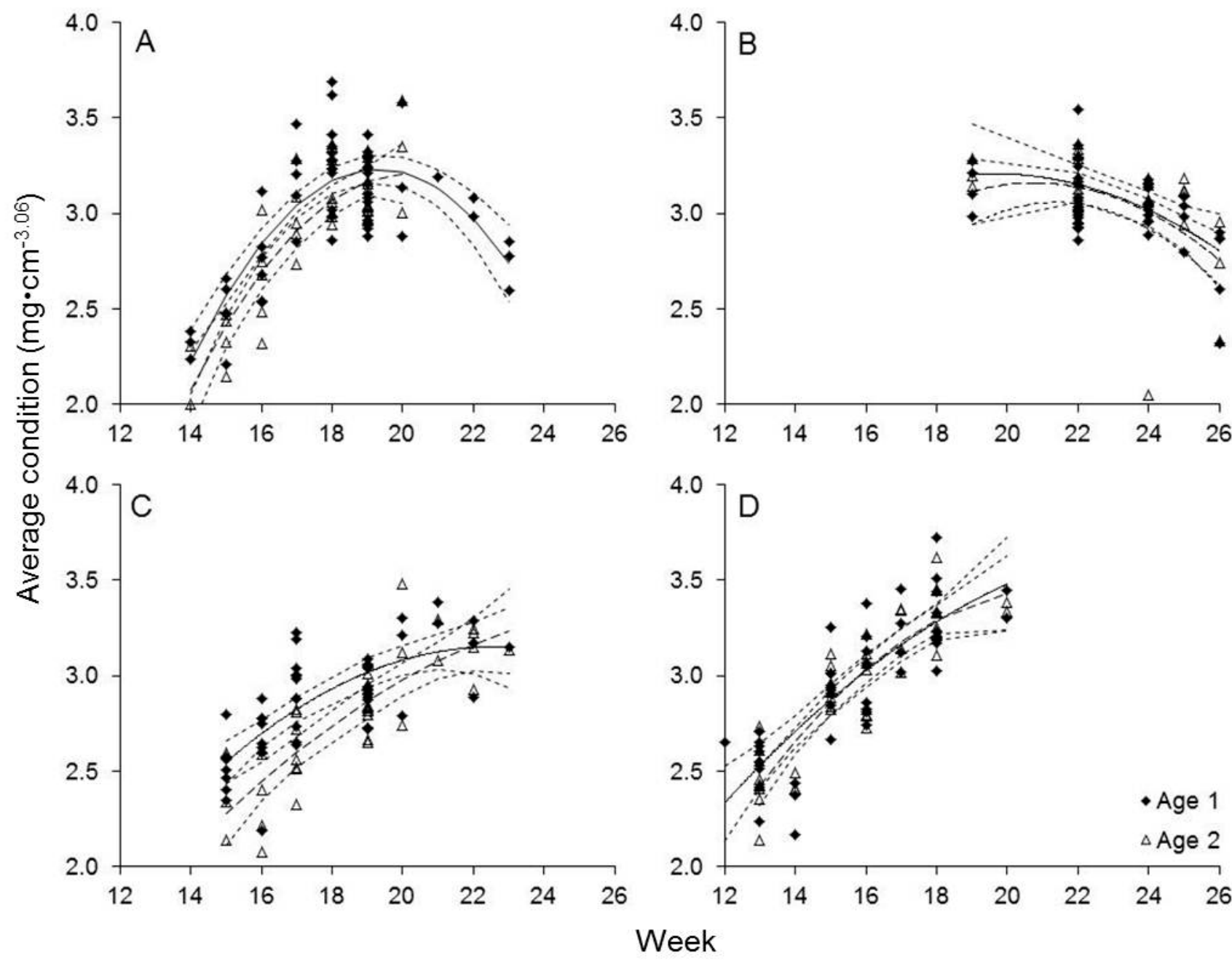

Fig. 9. 


\section{Supplementary material}

\section{Estimating season length}

3 Unfortunately, estimating season length while also estimating the von Bertalanffy growth

4 parameters is not straight forward. Instead, we estimated season length using only data

5 from cohorts sampled in two consecutive years with at least 5 weeks of sampling in each

6 year. For these cohorts, time spend buried between the first and second growth season

7 was estimated by minimizing the squared deviation between observed and predicted

8 length, $\hat{l}$ :

$9 \hat{l}=L_{\infty}\left(1-\exp \left(-K\left(t_{g}-t_{0}\right)\right)\right)=L_{\infty}\left(1-\exp \left(-K\left(t_{a}-t_{y} t_{b}-t_{0}\right)\right)\right)$

where $L_{\infty}, K$ and $t_{0}$ are the parameters of the von Bertalanffy growth equation describing

11 maximum length, intrinsic growth rate and the theoretical age at length 0 , respectively.

12 As the fishing grounds fulfilling the requirement for number of samples were all situated

13 in the Dogger Bank complex, the parameters were assumed to be the same for all

14 grounds and estimated in a common model using PROC NLIN in SAS version 9.2 for

15 Windows. To avoid including cohorts which did not add information to the relationship,

16 the model was initially fitted for each cohort and fishing ground separately. Fishing

17 ground/cohort combinations for which the model failed to converge were eliminated

18 from further analyses.

Six cohorts were sampled in 5 weeks in each of two consecutive years: N. W. Rough, 2004, 2005, 2006 and 2007 cohorts, Southernmost Rough, 2004 cohort and Stenkanten,

212005 cohort. Of these, the model failed to converge for N.W. Rough 2005 and 2007 and 
22 these cohorts were excluded from further analyses. The length of the growth season

23 estimated in common for all cohorts and fishing grounds was 15.0 weeks (standard error

24 4.2). The data used are seen in fig. S1.

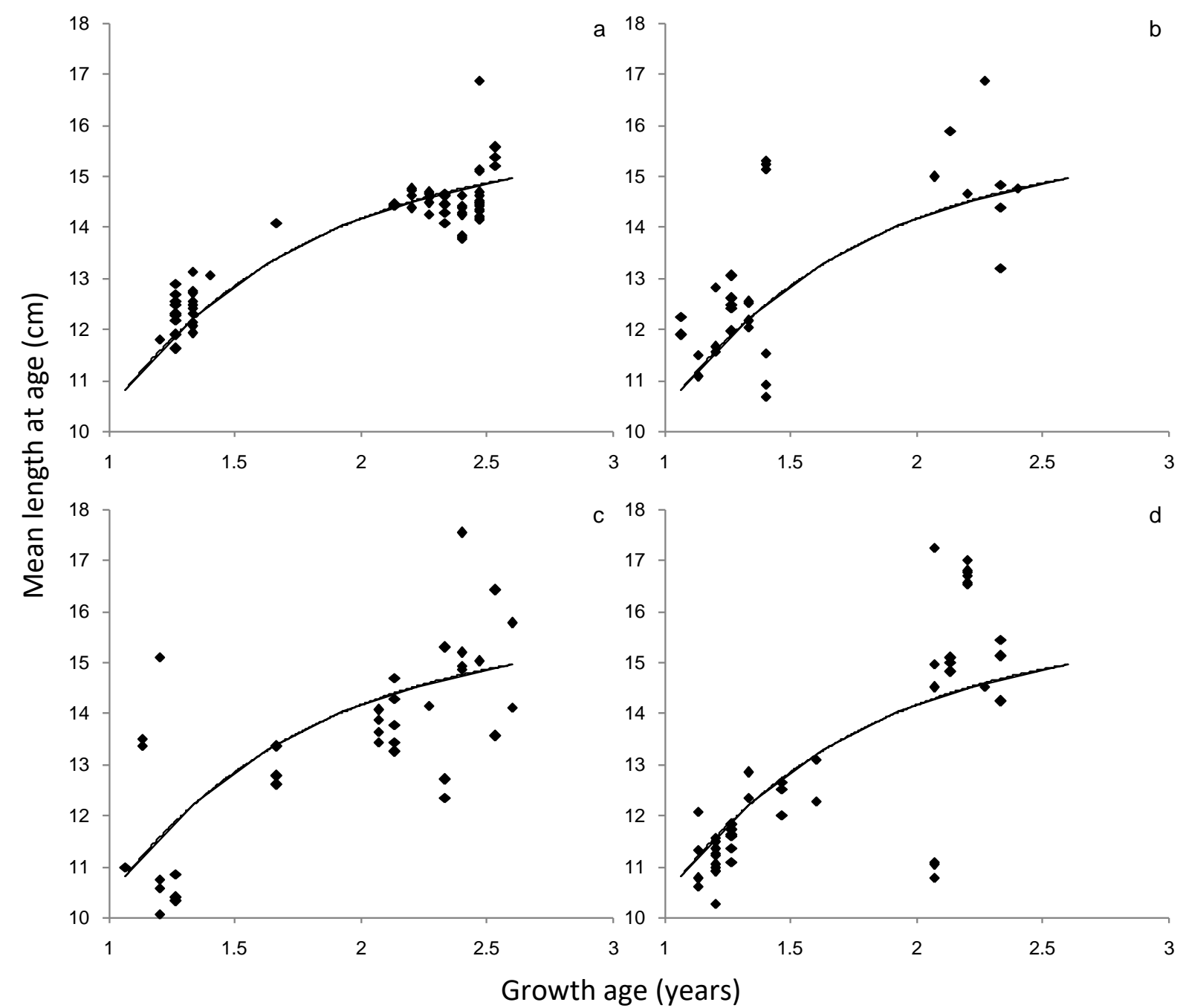

26 Fig. S1. Length as a function of estimated growth age (growth season length=15 weeks,

27 age $0=$ week 12 of the year of hatching). N. W. Rough 2004 and 2006 cohorts (a and b,

28 respectively), Southernmost Rough 2007 cohort (c) and Stenkanten 2005 cohort (d). Line 29 is estimated common von Bertalanffy growth curve. 
32 Forward elimination tests of effect on von Bertalanffy parameters. Models selected are marked in bold. The total number of observations is 3856.

\begin{tabular}{|c|c|c|c|c|c|c|c|c|c|c|c|c|c|c|}
\hline $\begin{array}{l}\text { Model parameters } \\
\text { included together } \\
\text { with tested effect: }\end{array}$ & $\begin{array}{l}\text { DF model } \\
\text { addition }\end{array}$ & & $\begin{array}{l}\text { idual sur } \\
\text { squares }\end{array}$ & & & $\mathrm{F}$ & & Probab & lity of effect & being 0 & & $\mathrm{R}^{2}$ & & $\begin{array}{c}\text { Cumm } \\
\text { ulated } \\
R^{2}\end{array}$ \\
\hline Tested effect on & & $\mathrm{K}$ & $\mathrm{L}_{\infty}$ & $t_{0}$ & $\mathrm{~K}$ & $\mathrm{~L}_{\infty}$ & $t_{0}$ & $\mathrm{~K}$ & $\mathrm{~L}_{\infty}$ & $t_{0}$ & $\mathrm{~K}$ & $\mathrm{~L}_{\infty}$ & $t_{0}$ & \\
\hline $\begin{array}{l}\text { Tested effect of } \\
\text { second degree } \\
\text { polynomial in: } \\
\text { Density }\end{array}$ & 2 & 7903 & 7819 & 8095 & 224 & 247 & 173 & $<0.0001$ & $<0.0001$ & $<0.0001$ & 0.104 & 0.114 & 0.082 & \\
\hline Bottom temperature & 2 & 7976 & 7901 & 7974 & 204 & 225 & 205 & $<0.0001$ & $<0.0001$ & $<0.0001$ & 0.096 & 0.104 & 0.096 & \\
\hline SST & 2 & 7936 & 8453 & 8096 & 215 & 84 & 173 & $<0.0001$ & $<0.0001$ & $<0.0001$ & 0.100 & 0.042 & 0.082 & \\
\hline Copepods & 2 & 7856 & 8112 & 8028 & 6883 & 169 & 191 & $<0.0001$ & $<0.0001$ & $<0.0001$ & 0.110 & 0.081 & 0.09 & \\
\hline Protozoo & 2 & 8318 & 8246 & 8339 & 117 & 135 & 112 & $<0.0001$ & $<0.0001$ & $<0.0001$ & 0.057 & 0.065 & 0.055 & \\
\hline
\end{tabular}




\begin{tabular}{|c|c|c|c|c|c|c|c|c|c|c|c|c|c|c|}
\hline Latitude & 2 & 8319 & 8161 & 8312 & 116 & 156 & 118 & $<0.0001$ & $<0.0001$ & $<0.0001$ & 0.057 & 0.075 & 0.058 & \\
\hline longitude & 2 & 6808 & 7081 & 7096 & 570 & 473 & 468 & $<0.0001$ & $<0.0001$ & $<0.0001$ & 0.228 & 0.197 & 0.196 & 0.228 \\
\hline Depth & 2 & 8701 & 8743 & 8659 & 27 & 17 & 36 & $<0.0001$ & $<0.0001$ & $<0.0001$ & 0.014 & 0.009 & 0.019 & \\
\hline
\end{tabular}

\begin{tabular}{|c|c|c|c|c|c|c|c|c|c|c|c|c|c|c|}
\hline $\begin{array}{l}\text { Model parameters } \\
\text { included together } \\
\text { with tested effect: } \\
\mathrm{K}, \mathrm{L}_{\infty}, \mathrm{t}_{0}, \mathrm{~K} 2^{\text {nd }} \text { degree } \\
\text { polynomial in } \\
\text { longitude } \\
\text { Tested effect on }\end{array}$ & $\begin{array}{l}\text { DF model } \\
\text { addition }\end{array}$ & $\operatorname{Res}$ & $\begin{array}{l}\text { dual su } \\
\text { square }\end{array}$ & of & K & 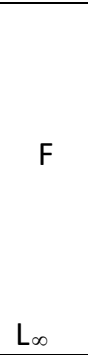 & $t_{0}$ & Probabi & ity of effec & being 0 & K & $\mathrm{R}^{2}$ & $t_{0}$ & $\begin{array}{c}\text { Cumm } \\
\text { ulated } \\
\mathrm{R}^{2}\end{array}$ \\
\hline $\begin{array}{l}\text { Tested effect of } \\
\text { second degree } \\
\text { polynomial in } \\
\text { Density }\end{array}$ & 2 & 6660 & 6651 & 6737 & 43 & 45 & 20 & $<0.0001$ & $<0.0001$ & $<0.0001$ & 0.017 & 0.018 & 0.008 & \\
\hline Bottom temperature & 2 & 5960 & 5916 & 6156 & 274 & 290 & 204 & $<0.0001$ & $<0.0001$ & $<0.0001$ & 0.096 & 0.101 & 0.074 & \\
\hline SST & 2 & 6636 & 6789 & 6725 & 5956 & 5 & 24 & $<0.0001$ & 0.0045 & $<0.0001$ & 0.019 & 0.002 & 0.009 & \\
\hline copepods & 2 & 6677 & 6720 & 6685 & 38 & 25 & 35 & $<0.0001$ & $<0.0001$ & $<0.0001$ & 0.015 & 0.01 & 0.014 & \\
\hline
\end{tabular}




\begin{tabular}{|c|c|c|c|c|c|c|c|c|c|c|c|c|c|c|}
\hline protozoo & 2 & 6602 & 6641 & 6638 & 60 & 48 & 49 & $<0.0001$ & $<0.0001$ & $<0.0001$ & 0.023 & 0.019 & 0.019 & \\
\hline latitude & 2 & 5720 & 5616 & 5874 & 366 & 409 & 306 & $<0.0001$ & $<0.0001$ & $<0.0001$ & 0.123 & 0.135 & 0.106 & 0.364 \\
\hline longitude & 2 & & 6628 & 6682 & & 52 & 36 & & $<0.0001$ & $<0.0001$ & & 0.02 & 0.014 & \\
\hline Depth & 2 & 6204 & 6078 & 6322 & 187 & 231 & 148 & $<0.0001$ & $<0.0001$ & $<0.0001$ & 0.068 & 0.083 & 0.055 & \\
\hline longitude ${ }^{3}+$ longitude ${ }^{4}$ & 2 & 6528 & 6778 & 6762 & 83 & 9 & 13 & $<0.0001$ & 0.0002 & $<0.0001$ & 0.032 & 0.003 & 0.005 & \\
\hline
\end{tabular}

\begin{tabular}{|c|c|c|c|c|c|c|c|c|c|c|c|c|c|c|}
\hline $\begin{array}{l}\text { Model parameters } \\
\text { included together } \\
\text { with tested effect: } \\
\mathrm{K}, \mathrm{L}_{\infty}, \mathrm{t}_{0}, \mathrm{~K} 2^{\text {nd }} \text { degree } \\
\text { polynomial in } \\
\text { longitude, } \mathrm{L}_{\infty} 2^{\text {nd }} \\
\text { degree polynomial in } \\
\text { latitude } \\
\text { Tested effect on }\end{array}$ & $\begin{array}{l}\text { DF model } \\
\text { addition }\end{array}$ & $\operatorname{Re}$ & $\begin{array}{l}\text { idual sur } \\
\text { squares }\end{array}$ & of & $\mathrm{K}$ & 更 & $t_{0}$ & Probab & lity of effec & being 0 & K & $\mathrm{L}_{\infty}$ & $t_{0}$ & $\begin{array}{c}\text { Cumm } \\
\text { ulated } \\
\mathrm{R}^{2}\end{array}$ \\
\hline $\begin{array}{l}\text { Tested effect of } \\
\text { second degree } \\
\text { polynomial in } \\
\text { Density }\end{array}$ & 2 & 5603 & 5579 & 5612 & 4 & 13 & 1 & 0.0132 & $<0.0001$ & 0.2994 & 0.001 & 0.004 & 0 & \\
\hline Bottom temperature & 2 & 5544 & 5588 & 5552 & 25 & 9 & 22 & $<0.0001$ & $<0.0001$ & $<0.0001$ & 0.008 & 0.003 & 0.007 & \\
\hline
\end{tabular}




\begin{tabular}{|c|c|c|c|c|c|c|c|c|c|c|c|c|c|c|}
\hline SST & 2 & 5254 & 5252 & 5273 & 132 & 133 & 125 & $<0.0001$ & $<0.0001$ & $<0.0001$ & 0.041 & 0.041 & 0.039 & \\
\hline copepods & 2 & 5546 & 5553 & 5538 & 24 & 22 & 27 & $<0.0001$ & $<0.0001$ & $<0.0001$ & 0.008 & 0.007 & 0.009 & \\
\hline protozoo & 2 & 5518 & 5567 & 5552 & 34 & 17 & 22 & $<0.0001$ & $<0.0001$ & $<0.0001$ & 0.011 & 0.005 & 0.007 & \\
\hline latitude & 2 & 5574 & & 5578 & 14 & & 13 & $<0.0001$ & & $<0.0001$ & 0.005 & & 0.004 & \\
\hline longitude & 2 & & 5591 & 5381 & & 9 & 84 & & 0.0002 & $<0.0001$ & & 0.003 & 0.027 & \\
\hline Depth & 2 & 5475 & 5476 & 5454 & 49 & 49 & 57 & $<0.0001$ & $<0.0001$ & $<0.0001$ & 0.016 & 0.016 & 0.018 & \\
\hline $\begin{array}{l}\text { longitude }{ }^{3} \\
+ \text { longitude }\end{array}$ & 2 & 5429 & 5423 & 5603 & 66 & 68 & 4 & $<0.0001$ & $<0.0001$ & 0.0117 & 0.021 & 0.022 & 0.001 & \\
\hline latitude $^{3}+$ latitude $^{4}$ & 2 & 5580 & 5235 & 5527 & 12 & 140 & 31 & $<0.0001$ & $<0.0001$ & $<0.0001$ & 0.004 & 0.043 & 0.01 & 0.407 \\
\hline Latitude*longitude & 2 & 5565 & 5477 & 5590 & 18 & 49 & 9 & $<0.0001$ & $<0.0001$ & 0.0001 & 0.006 & 0.016 & 0.003 & \\
\hline $\begin{array}{l}\text { Model parameters } \\
\text { included together } \\
\text { with tested effect: } \\
\mathrm{K}, \mathrm{L}_{\infty}, \mathrm{t}_{0}, \mathrm{~K} 2^{\text {nd }} \text { degree } \\
\text { polynomial in } \\
\text { longitude, } \mathrm{L}_{\infty} 4^{\text {th }} \\
\text { degree polynomial in } \\
\text { latitude }\end{array}$ & $\begin{array}{l}\text { DF model } \\
\text { addition }\end{array}$ & Res & $\begin{array}{l}\text { dual sur } \\
\text { quares }\end{array}$ & & & $\mathrm{F}$ & & Probab & $y$ of effect & eing 0 & & $\mathrm{R}^{2}$ & & $\begin{array}{c}\text { Cumm } \\
\text { ulated } \\
\mathrm{R}^{2}\end{array}$ \\
\hline
\end{tabular}




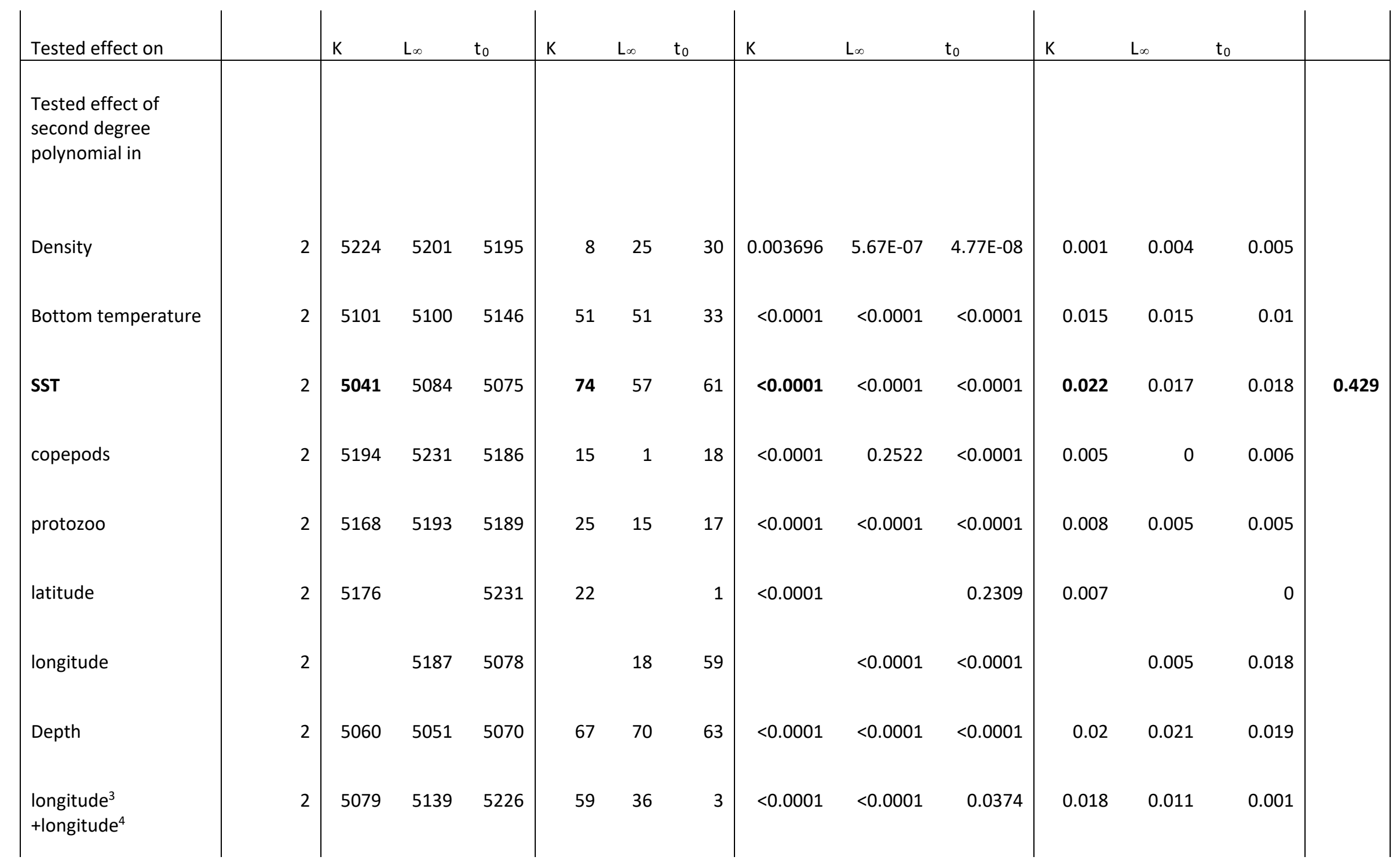




\begin{tabular}{|c|c|c|c|c|c|c|c|c|c|c|c|c|c|}
\hline latitude ${ }^{3}+$ latitude ${ }^{4}$ & 2 & 5190 & 5235 & 5235 & 17 & & 0 & $<0.0001$ & & 0.9224 & 0.005 & 0 & 0 \\
\hline Latitude*longitude & 2 & 5098 & 5105 & 5208 & 52 & 49 & 10 & $<0.0001$ & $<0.0001$ & $<0.0001$ & 0.016 & 0.015 & 0.003 \\
\hline latitude $^{5}+$ latitude 6 & 2 & 5191 & 5167 & 5230 & 16 & 25 & 2 & $<0.0001$ & $<0.0001$ & 0.1292 & 0.005 & 0.008 & 0.001 \\
\hline
\end{tabular}

\begin{tabular}{|c|c|c|c|c|c|c|c|c|c|c|c|c|c|c|}
\hline $\begin{array}{l}\text { Model parameters } \\
\text { included together } \\
\text { with tested effect: } \\
\mathrm{K}, \mathrm{L}_{\infty}, \mathrm{t}_{0}, \mathrm{~K} 2^{\text {nd }} \text { degree } \\
\text { polynomial in } \\
\text { longitude and SST, } \mathrm{L}_{\infty} \\
4^{\text {th }} \text { degree } \\
\text { polynomial in latitude } \\
\text { Tested effect on }\end{array}$ & $\begin{array}{l}\text { DF model } \\
\text { addition }\end{array}$ & Res & $\begin{array}{l}\text { idual su } \\
\text { square }\end{array}$ & of & $\mathrm{K}$ & $\mathrm{L}_{\infty}$ & $t_{0}$ & Probab & lity of effec & being 0 & K & $\mathrm{L}_{\infty}$ & $t_{0}$ & $\begin{array}{c}\text { Cumm } \\
\text { ulated } \\
\mathrm{R}^{2}\end{array}$ \\
\hline $\begin{array}{l}\text { Tested effect of } \\
\text { second degree } \\
\text { polynomial in } \\
\text { Density }\end{array}$ & 2 & 5024 & 5017 & 5004 & 7 & 9 & 14 & 0.0014 & $<0.0001$ & $<0.0001$ & 0.002 & 0.003 & 0.004 & \\
\hline Bottom temperature & 2 & 4785 & 4802 & 4870 & 103 & 0 & 0 & $<0.0001$ & 1 & 1 & 0.029 & 0.027 & 0.019 & \\
\hline SST & 2 & & 5016 & 5033 & & 10 & 3 & & $<0.0001$ & 0.0400 & & 0.003 & 0.001 & \\
\hline copepods & 2 & 4985 & 5019 & 4987 & 22 & 8 & 21 & $<0.0001$ & 0.0002 & $<0.0001$ & 0.006 & 0.003 & 0.006 & \\
\hline
\end{tabular}




\begin{tabular}{|c|c|c|c|c|c|c|c|c|c|c|c|c|c|c|}
\hline protozoo & 2 & 4963 & 4986 & 4986 & 30 & 21 & 21 & $<0.0001$ & $<0.0001$ & $<0.0001$ & 0.009 & 0.006 & 0.006 & \\
\hline Latitude & 2 & 4959 & & 5040 & 32 & 0 & 1 & $<0.0001$ & & 0.5776 & 0.009 & & 0.00 & \\
\hline Longitude & 2 & & 5027 & 4969 & 0 & 5 & 28 & & 0.0053 & $<0.0001$ & & 0.002 & 0.008 & \\
\hline Depth & 2 & 4763 & 4770 & 4824 & 112 & 1 & 87 & $<0.0001$ & 0.3680 & $<0.0001$ & 0.032 & 0.031 & 0.025 & 0.46 \\
\hline latitude ${ }^{3}+$ latitude ${ }^{4}$ & 2 & 4937 & & 5037 & 41 & & 2 & $<0.0001$ & & 0.2031 & 0.012 & & 0 & \\
\hline $\begin{array}{l}\text { longitude } \\
\text { +longitude }^{3}\end{array}$ & 2 & 5004 & 4995 & 5034 & 14 & 3 & 3 & $<0.0001$ & 0.0499 & 0.0551 & 0.004 & 0.005 & 0.001 & \\
\hline $\mathrm{SST}^{3}+\mathrm{SST}^{4}$ & 2 & 5015 & 5017 & 5041 & 10 & 4 & 0 & $<0.0001$ & 0.0184 & 0.9962 & 0.003 & 0.003 & 0 & \\
\hline Latitude*longitude & 2 & 4928 & 4965 & 5023 & 44 & 5 & 7 & $<0.0001$ & 0.0068 & 0.0012 & 0.013 & 0.009 & 0.002 & \\
\hline latitude $^{5}+$ latitude 6 & 2 & 4959 & 4943 & 5039 & 32 & 5 & 1 & $<0.0001$ & 0.0067 & 0.4225 & 0.009 & 0.011 & 0 & \\
\hline
\end{tabular}

\begin{tabular}{|c|c|c|c|c|c|c|}
\hline $\begin{array}{l}\text { Model parameters } \\
\text { included together } \\
\text { with tested effect: } \\
\mathrm{K}, \mathrm{L}_{\infty}, \mathrm{t}_{0}, \mathrm{~K} 2^{\text {nd }} \text { degree } \\
\text { polynomial in } \\
\text { longitude, SST and } \\
\text { depth, } \mathrm{L}_{\infty} 4^{\text {th }} \text { degree } \\
\text { polynomial in latitude }\end{array}$ & $\begin{array}{l}\text { DF model } \\
\text { addition }\end{array}$ & $\begin{array}{l}\text { Residual sum of } \\
\text { squares }\end{array}$ & $\mathrm{F}$ & Probability of effect being 0 & $\mathrm{R}^{2}$ & $\begin{array}{c}\text { Cumm } \\
\text { ulated } \\
\mathrm{R}^{2}\end{array}$ \\
\hline
\end{tabular}




\begin{tabular}{|c|c|c|c|c|c|c|c|c|c|c|c|c|c|}
\hline Tested effect on & & $\mathrm{K}$ & $\mathrm{L}_{\infty}$ & $t_{0}$ & $\mathrm{~K}$ & $\mathrm{~L}_{\infty}$ & $t_{0}$ & $\mathrm{~K}$ & $\mathrm{~L}_{\infty}$ & $t_{0}$ & $\mathrm{~K}$ & $\mathrm{~L}_{\infty}$ & 0 \\
\hline $\begin{array}{l}\text { Tested effect of } \\
\text { second degree } \\
\text { polynomial in } \\
\text { Density }\end{array}$ & 2 & 4760 & 4757 & 4752 & 1 & 2 & 4 & 0.3939 & 0.1109 & 0.0115 & 0.000 & 0.001 & 0.001 \\
\hline Bottom temperature & 2 & 4754 & 4740 & 4763 & 4 & 9 & 0 & 0.0245 & $<0.0001$ & 0.9722 & 0.001 & 0.003 & 0 \\
\hline SST & 2 & & 4738 & 4752 & & 10 & 4 & & $<0.0001$ & 0.0130 & 0 & 0.003 & 0.001 \\
\hline copepods & 2 & 4744 & 4760 & 4735 & 8 & 1 & 11 & 0.0005 & 0.4118 & $<0.0001$ & 0.002 & 0.000 & 0.003 \\
\hline protozoo & 2 & 4708 & 4736 & 4718 & 22 & 11 & 18 & $<0.0001$ & $<0.0001$ & $<0.0001$ & 0.006 & 0.003 & 0.005 \\
\hline latitude & 2 & 4727 & & 4759 & 14 & & 2 & $<0.0001$ & & 0.1928 & 0.004 & 0 & 0.001 \\
\hline Longitude & 2 & & 4742 & 4710 & & 8 & 21 & & 0.00021 & $<0.0001$ & & 0.002 & 0.006 \\
\hline Depth & 2 & & 4746 & 4738 & & 7 & 10 & & 0.0013 & $<0.0001$ & & 0.002 & 0.003 \\
\hline latitude $^{3}$ +latitude ${ }^{4}$ & 2 & 4717 & & 4757 & 19 & & 2 & $<0.0001$ & & 0.0829 & 0.005 & & 0.001 \\
\hline $\begin{array}{l}\text { longitude } \\
+ \text { longitude }^{4}\end{array}$ & 2 & 4728 & 4734 & 4754 & 14 & 12 & 4 & $<0.0001$ & $<0.0001$ & 0.0249 & 0.004 & 0.003 & 0.001 \\
\hline
\end{tabular}




\begin{tabular}{|c|c|c|c|c|c|c|c|c|c|c|c|c|c|}
\hline $\mathrm{SST}^{3}+\mathrm{SST}^{4}$ & 2 & 4754 & 4741 & 4759 & 3 & 9 & 1 & 0.0321 & 0.0002 & 0.2739 & 0.001 & 0.002 & 0.000 \\
\hline Depth $^{3}+$ Depth $^{4}$ & 2 & 4761 & 4745 & 4758 & 1 & 7 & 2 & 0.4742 & 0.0008 & 0.1252 & 0.000 & 0.002 & 0.001 \\
\hline latitude ${ }^{5}+$ latitude 6 & 2 & 4722 & 4695 & 4756 & 16 & 28 & 3 & $<0.0001$ & $<0.0001$ & 0.0813 & 0.005 & 0.008 & 0.001 \\
\hline Latitude*Iongitude & 2 & 4722 & 4707 & 4730 & 4754 & 23 & 13 & $<0.0001$ & $<0.0001$ & $<0.0001$ & 0.005 & 0.006 & 0.004 \\
\hline
\end{tabular}

